www.juridicas.unam.mx

\title{
El proceso de creación e incorporación de los estándares internacionales en materia de desaparición forzada de personas en México y su revisión por parte de Corte Interamericana de Derechos Humanos en el caso Rosendo Radilla*
}

\section{The Process of Creation and Implementation of the International Standards on Enforced} Disappearance of Persons in Mexico, and its Review by the Inter-American Court of Human Rights in the Case Rosendo Radilla

Carlos María Pelayo Moller**

SUMARIO: I. Introducción. II. La creación y desarrollo del marco jurídico internacional en torno a la desaparición forzada de personas. III. El proceso de incorporación de los estándares internacionales en materia de desaparición forzada en México. IV. El caso Rosendo Radilla ante la Corte Interamericana de Derechos Humanos. V. Las implicaciones de la sentencia en el caso Rosendo Radilla en el proceso de incorporación de los estándares internacionales en materia de desaparición forzada de personas en México. VI. Reflexiones finales. VII. Bibliografía.

* Artículo recibido el 6 de julio de 2011 y aprobado para publicación el 6 de octubre de 2011.

** Licenciado en Derecho por la Universidad Autónoma de Sinaloa; LL.M. en Derecho Internacional de los Derechos Humanos por la Universidad de Notre Dame; doctorando en el Instituto de Investigaciones Jurídicas de la UNAM.

Agradezco los consejos, orientación e ideas en este tema por parte de Douglass Cassel. Asimismo, agradezco los atinados comentarios deYuria Saavedra Álvarez, así como la revisión y discusión de algunas partes con Mónica Romero Attolini. Cualquier error que este artículo pueda contener es responsabilidad exclusiva del autor. 
Resumen: El caso de Rosendo Radilla ante la Corte Interamericana de Derechos Humanos es el marco ideal para explicar los procesos de creación y desarrollo del derecho internacional de los derechos humanos en casos de desaparición forzada de personas. Asimismo, el caso es ideal para explicar los procesos de incorporación del derecho internacional a nivel interno en México. La dinámica del Sistema Interamericano de Derechos Humanos hizo posible someter dicho proceso de incorporación a un escrutinio internacional con el fin de verificar su validez. Esto plantea un "retorno" para que dichos estándares de control puedan ser aplicados a nivel interno. El presente artículo tendrá como objetivo describir esos procesos así como realizar una crítica sobre los mismos; en especial, sobre su capacidad de producir un profundo cambio a nivel normativo tanto a nivel internacional y especialmente a nivel nacional.

Palabras clave: derechos humanos, desaparición forzada de personas, recepción del derecho internacional de los derechos humanos, justicia militar en México, Corte Interamericana de Derechos Humanos, caso Rosendo Radilla Pacheco.

ABSTRACT:The Rosendo Radilla case before the Inter-American Court of Human Rights is the perfect framework to explain the processes of creation and development of international human rights law in cases offorced disappearance. Also, the case is ideal to explain the processes of implementation of international law at the domestic level in Mexico. The dynamic of the Inter-American System of Human Rights made possible the submission of that process of implementation to an international scrutiny in order to verify its validity. This situation entails a "return" in order to apply these standards of control at the internal level. The purpose of this article is to describe these processes and make a critic on them. Especially, it will be discussed the capacity of these processes to produce a deep normative change at the international and mainly at the national level.

Descriptors: Human Rights, Forced Disappearance of Persons, Reception of international law of human rights, Military justice in Mexico, Inter-American Court of Human Rights, Radilla Pacheco Case.

RÉSUMÉ: L'affaire de Rosendo Radilla devant la Cour interaméricaine des droits de l'homme est le cadre idéal pour expliquer le processus de création et développement du droit international des droits humains dans les affaires de disparition forcée des personnes. De même, l'affaire est idéale pour expliquer le processus d'incorporation du droit international au droit interne au Mexique. La dynamique du système interaméricain des droits humains a permis de présenter le processus d'incorporation à un contrôle international afin de vérifier leur validité. Cela pose un «retour» pour que les normes puissent être appliquées au niveau interne. Cet article aura pour but de décrire ces processus, ainsi que réaliser une critique sur eux, en particulier sur sa capacité à produire un changement profond au niveau normatif tant au niveau international et en particulier au niveau national.

Mots-clés: Droits de l'Homme, la disparition forcée des personnes; réception du droit international des droits humains, la justice militaire au Mexique, la Cour interaméricaine des Droits de l'Homme, Affaire Rosendo Radilla Pacheco. 
Mejor será no regresar al pueblo, al edén subvertido que se calla en la mutilación de la metralla

Ramón López Velarde en El Retorno Maléfico

Era un 18 de mayo como a las 11 sería, en la plaza de Atoyac toda la gente corría, de ver a sus camaradas que uno tras otro caían

Rosendo Radilla en el corrido 18 de mayo

\section{INTRODUCCIÓN}

El fenómeno de la desaparición forzada no es algo nuevo en la historia de la humanidad. Sin embargo, desde hace algunas décadas ha cobrado importancia como tema de interés internacional. Primero, en instituciones de carácter principalmente político, y subsecuentemente en instancias jurisdiccionales a nivel regional.

El caso de Rosendo Radilla ante la Corte Interamericana de Derechos Humanos es el marco ideal para explicar los procesos de creación y desarrollo del derecho internacional de los derechos humanos en casos de desaparición forzada de personas. Asimismo, el caso es ideal para explicar los procesos de incorporación del derecho internacional a nivel interno en México. La dinámica del Sistema Interamericano de Derechos Humanos hizo posible someter dicho proceso de incorporación a un escrutinio internacional con el fin de verificar su validez. Esto plantea un "retorno" para que dichos estándares de control puedan ser aplicados a nivel interno. El presente artículo tendrá como objetivo describir esos procesos así como realizar una crítica sobre los mismos; en especial, sobre su capacidad de producir un profundo cambio a nivel normativo tanto a nivel internacional y especialmente a nivel nacional. 


\section{LA CREACIÓN Y DESARROLLO DEL MARCO JURÍDICO INTERNACIONAL}

EN TORNO A LA DESAPARICIÓN FORZADA DE PERSONAS

El crimen de desaparición forzada de personas no es endémico de una región particular del mundo. ${ }^{1}$ Sin embargo, debido a diferentes circunstancias históricas, la definición y alcance de este concepto empezó a formarse y enfocarse en la situación de varios países latinoamericanos; primero por las Naciones Unidas y posteriormente por el Sistema Interamericano de Derechos Humanos.

\section{Desarrollo y evolución del concepto de desaparición forzada} de personas en la Organización de las Naciones Unidas

Al momento en que los primeros instrumentos sobre derechos humanos fueron redactados y aprobados, la práctica de la desaparición forzada no había sido identificada como un crimen que impactara la conciencia de la comunidad internacional. ${ }^{2}$ Sin bien, durante la década de los cincuenta, la Organización de las Naciones Unidas empezó a reconocer las implicaciones legales y fácticas de la desaparición forzada de personas respecto a los derechos de las personas; ${ }^{3}$ fue hasta los años setenta que la comunidad internacional, a través de la Asamblea General, empezó a ver este problema de manera independiente de otras violaciones a los derechos humanos.

\section{A. La Resolución 33/173 de 1978 de la Asamblea General de las Naciones Unidas}

Las desapariciones forzadas ocurridas en Guatemala durante los años sesenta y las ocurridas en Chile y en Argentina en los años setenta fue-

U.N. Econ. \& Soc. Council [ECOSOC], Commission on Human Rights, Working Group on Enforced or Involuntary Disappearances: Annual Report on Civil and political rights including the questions of: Disappearances and Summary Executions. UN Doc. E/ CN.4/2006/56 (Dec. 27, 2005) p. 9, parr. 4.

2 Méndez, Juan E. y Vivanco, José Miguel, "Disappearances and the Inter-American Court: Reflections on a litigation experience”, Hamline Law Review, núm. 13, 1990, p. 512.

Ibidem, p. 513. 
ron parte de una política gubernamental de represión extendida, a partir de ese momento, este fenómeno empezó a ser una preocupación a nivel internacional. ${ }^{4}$

La primera iniciativa para atacar este problema fue impulsada por las delegaciones de Canadá y del Reino Unido en la Asamblea General de las Naciones Unidas con la asistencia del secretario general de la Organización. Ambas delegaciones co-patrocinaron una resolución que presentaron al Comité de Derechos Humanos. ${ }^{5}$ Esta iniciativa eventualmente se convirtió en la Resolución 33/173, adoptada por la Asamblea General el 20 de diciembre de 1978, después de largas discusiones para llegar a un consenso respecto a los términos del texto. ${ }^{6}$ Esta resolución, si bien no era un instrumento de carácter judicial, se convirtió en la primera condena política mundial a esta práctica, que para esa época era ya usual en varios regímenes latinoamericanos.

La resolución, esencialmente, llamó a los gobiernos a destinar los recursos necesarios para la búsqueda de personas desaparecidas, a la aplicación de la ley y al respeto a los derechos humanos de las personas. Asimismo, invitaba a cooperar con otras naciones y organizaciones internacionales en esta materia. ${ }^{7}$ Además, caracterizó este crimen como una "situación continua de grave y flagrante violación a los derechos humanos". ${ }^{8}$

La resolución también requirió que la Comisión de Derechos $\mathrm{Hu}$ manos de las Naciones Unidas abordara los problemas de la desaparición forzada de personas con el fin de realizar recomendaciones en este asunto. ${ }^{9}$ No obstante el gran avance que significó esta resolución, se presentaron dos importantes problemas a resolver: primero, la nece-

Livermore, J. Daniel y Ramcharan, B. G., "Enforced or involuntary Disappearances"An Evaluation of a Decade of United Nations Action, Canadian Human Rights Year Book, 1989-1990, p. 218.

5 Idem.

6 Idem.

${ }^{7}$ Declaración sobre la protección de todas las personas contra las desapariciones forzadas de las Naciones Unidas, G.A. Res. 47/133, U.N. Doc. A/Res/47/133 (Dec. 18 1992) 1 inciso $a$ al $c$.

8 Human Rights in Chile, G.A. Res 34/179 (1979).

9 Idem. 
sidad de definir qué actos debían ser considerados como desaparición forzada y segundo, la determinación de los mecanismos del Comité. ${ }^{10}$

Con posterioridad a esta Resolución, el Consejo Económico y Social en la Resolución 1979/38 del 10 de mayo de 1979 consideró la desaparición forzada de personas como un asunto prioritario. También en la Resolución 5 B (XXXII) de la Sub-Comisión para Prevenir la Discriminación de las Minorías se hizo lo mismo.

\section{B. La Comisión de Derechos Humanos de las Naciones Unidas}

A comienzos de la década de los años setenta, después del golpe de Estado del general Augusto Pinochet en Chile, la Comisión de Derechos Humanos de las Naciones Unidas comenzó a realizar una serie de informes e investigaciones sobre la situación de los derechos humanos en el continente con una activa participación de organizaciones no gubernamentales. ${ }^{11}$

Incluso antes de la Resolución 33/173, la Comisión ya se encontraba preocupada por el tema de la desaparición forzada de personas; sin embargo, su estudio estaba disgregado en una serie de diferentes tópicos de derechos humanos.

Durante esta época, una de las más notables y definitivas contribuciones de la Comisión fue la misión de investigación sin precedentes del Grupo de Trabajo de las Naciones Unidas en Chile, en 1978, que estuvo enfocada particularmente en casos de desaparición forzada. Posteriormente, la Comisión nombró dos expertos para examinar "el destino de los extraviados y desaparecidos en Chile". ${ }^{12}$

En 1980, las delegaciones nacionales, organizaciones no gubernamentales y la Secretaría General de las Naciones Unidas se enfocaron en la adopción de un instrumento internacional que permitiera tomar acciones concretas a la comunidad internacional en casos de desapari-

10 Livermore, J. Daniel y Ramcharan, B. G., op. cit, , p. 219.

11 Brody, Reed y González, Felipe, Nunca Más: An analysis of International Instruments on “Disappearances”, Human Rights, Quaterly, núm. 9, 1997, p. 367.

12 Study of reported violations of human rights in Chile, with particular reference to torture and other cruel, inhuman or degrading treatment or punishment, 6(b) Chap XXIV E/1979/36 (1979). 
ciones forzadas. ${ }^{13}$ Sin embargo, estos esfuerzos fueron obstaculizados directamente por la delegación Argentina en la Comisión de Derechos Humanos, situación que provocó una demora de dos años en el trabajo de este organismo.

Las partes acordaron la creación de un mecanismo especial con la misión de llevar a cabo estas investigaciones bajo un procedimiento confidencial, muy similar al de las denuncias bajo el procedimiento 1503 de Consejo Económico y Social, fue así como surgió el Grupo de Trabajo de Desapariciones Forzadas o Involuntarias. ${ }^{14}$

En adición a la conformación del Grupo de Trabajo, la Comisión de Derechos Humanos y otros organismos dependientes de las Naciones Unidas jugaron un rol importante al documentar y denunciar desapariciones forzosas desde la década de los ochenta. ${ }^{15}$

\section{El Grupo de Trabajo de Desapariciones forzadas o involuntarias}

El Grupo de Trabajo de Desapariciones Forzadas o Involuntarias, creado en 1980 por la Comisión de Derechos Humanos, ${ }^{16}$ se convirtió en el primer mecanismo temático destinado a lidiar con este tipo específico de violación a los derechos humanos ocurrido a escala global. ${ }^{17}$ En sus inicios, su creación levantó gran expectación, lo que llevó a que algunos expertos llegaran a considerar a este mecanismo como "lo más cercano posible a un habeas corpus internacional". ${ }^{18}$

13 Livermore, J. Daniel y Ramcharan, B. G, op. cit., p. 220.

14 Idem.

15 Por ejemplo, en relación con las leyes de amnistía en Argentina. Véase: Communication 275/1988: Argentina CCPR/C/38/D/275/1988 (April 4, 1990) En general también consúltese: Pérez Solla, María Fernanda, "Enforced Disappearances before Argentinean Tribunals: New Developments in an Endless fight for Justice", South African Journal on Human Rights, núm. 19, 2003. p. 693.

16 U.N. Econ. \& Soc. Council [ECOSOC], Commission on Human Rights, Resolution 20 (XXXVI) Question of missing and disappeared persons (Feb. 29, 1980).

17 U.N. Econ. \& Soc. Council [ECOSOC], Commission on Human Rights, Working Group on Enforced Disappearance: Fact Sheet (Rev.2) Enforced or Involuntary Disappearances.

18 Berman, Maureen y Clark, Roger, "State terrorism: Disappearances”, Rutgers Law Journal, núm. 13, 1982, p. 599. 
Originalmente, el Grupo fue establecido por un periodo de un año y se conformó por cinco miembros. ${ }^{19}$ Su misión esencial era recibir información de gobiernos, organizaciones intergubernamentales y organizaciones humanitarias, ${ }^{20}$ con la discrecionalidad necesaria ${ }^{21}$ para clarificar el destino o la suerte de las personas reportadas como desaparecidas. ${ }^{22}$

El mandato inicial otorgado en 1980 se amplió gradual pero considerablemente por parte de la Comisión de Derechos Humanos. Por ejemplo, la Resolución 2004/40, ${ }^{23}$ alentó y solicitó al grupo el poner atención a casos específicos de desaparición forzada perpetrados en contra de niños, defensores de derechos humanos y mujeres. ${ }^{24}$

Una función importante del Grupo de Trabajo ha sido la realización de visitas in situ a países. Los objetivos del Grupo de Trabajo han sido: sostener reuniones con autoridades gubernamentales, organizaciones no gubernamentales y familiares de personas desaparecidas, con el fin de analizar el fenómeno de las desapariciones forzadas. ${ }^{25}$ Después de cada visita, el Grupo de Trabajo emite un informe y realiza recomendaciones específicas respecto a la situación particular del país visitado. En marzo de 2011 el Grupo de Trabajo realizó una visita a México, país que no había visitado desde 1982, en la parte final de este escrito se comentarán algunos aspectos relevantes de dicha visita.

19 U.N. Econ. \& Soc. Council [ECOSOC], Commission on Human Rights, Resolution 20 (XXXVI) Question of missing and disappeared persons (Feb. 29, 1980) parr. 1.

20 Ibidem, párr. 3.

21 Ibidem, párr. 6.

22 U.N. Econ. \& Soc. Council [ECOSOC], Commission on Human Rights, Working Group on Enforced or Involuntary Disappearances: Annual Report on Civil and political rights including the questions of: Disappearances and Summary Executions. UN Doc. E/ CN.4/2006/56 (Dec. 27, 2005), p. 9, párr. 10.

${ }^{23}$ U.N. Econ. \& Soc. Council [ECOSOC], Commission on Human Rights, Resolution 2004/40 Enforced or involuntary disappearances (19 de abril de 2004).

${ }^{24}$ Idem.

25 En su visita a México en los años ochenta, el Grupo de Trabajo contactó autoridades gubernamentales, así como a asociaciones de familiares de desaparecidos. Aunque la visita del grupo no trajo por sí misma nueva información, la visita motivó a que el gobierno mexicano rindiera cuentas al Grupo de Trabajo sobre 62 de los 70 casos transmitidos en esa época tanto antes como después de la misión. Véase Rodley, Nigel S., United Nations Actions and Procedures Against "Disappearances", Summary or Arbitrary Executions, and Torture, Human. Rights. Quaterly, núm. 8, 1986, p. 708 . 
El Grupo de Trabajo ha evolucionado a los largo de los años producto de varias discusiones respecto a seis asuntos principales, a saber: cobertura global, publicidad (en lugar de la "discreción” requerida por el procedimiento 1503), su funcionamiento, las fuentes de información, las respuestas de los Estados y las recomendaciones de la Comisión o Sub-Comisión respecto a graves situaciones. ${ }^{26}$

El Grupo de Trabajo tiene como propósito tomar acciones inmediatas en casos de intimidación, persecución o represalias en contra de familiares de personas desaparecidas. Igualmente interviene a favor de grupos de personas que buscan a sus familiares o que buscan medidas de reparación. ${ }^{27}$ Los casos reportados dentro de los primeros tres meses son tratados como urgentes y transmitidos inmediatamente al país correspondiente. ${ }^{28}$

Otra función importante del Grupo de Trabajo es la publicación anual de un reporte con sus actividades. Esos documentos no sólo proveen una visión general de la situación mundial respecto a este tema, sino que también presentan datos específicos de los países analizados. ${ }^{29}$ Finalmente, el Grupo de Trabajo ha emitido una serie de observaciones generales interpretando y adaptando el texto de la Declaración sobre la protección de todas las personas contra las desapariciones forzadas de las Naciones Unidas a los desarrollos más recientes en esta materia en diferentes cortes internacionales, otorgándole a este instrumento un carácter universal a través de una interpretación progresiva. ${ }^{30}$

26 Livermore, J. Daniel y Ramcharan, B. G, op. cit., p. 222.

27 U.N. Econ. \& Soc. Council [ECOSOC], Commission on Human Rights, Working Group on Enforced or Involuntary Disappearances: Annual Report on Civil and political rights including the questions of: Disappearances and Summary Executions. UN Doc. E/ CN.4/2006/56 (Dec. 27, 2005), p. 10, párr. 11.

28 Ibidem, p. 10 párr. 10.

29 Idem.

${ }^{30}$ Véanse por ejemplo: U.N. Econ. \& Soc. Council [ECOSOC], Commission on Human Rights, Working Group on Enforced or Involuntary Disappearances: Compilation of General Comments on the Declaration on the Protection of All Persons from Enforced Disappearance. 


\section{La Declaración sobre la protección de todas las personas}

contra las desapariciones forzadas de las Naciones Unidas de 1992

La Declaración sobre la Protección de Todas las Personas contra las Desapariciones Forzadas de las Naciones Unidas es uno de los documentos más importantes en el reconocimiento de este crimen como una especial y particular ofensa en contra de la humanidad. ${ }^{31}$

Aunque no proporciona una definición exacta de este crimen, la Declaración antes mencionada describe los elementos y consecuencias de esta práctica. ${ }^{32}$ También discute los derechos que son puestos en riesgo ${ }^{33}$ y eventualmente vulnerados a raíz de este delito. ${ }^{34}$ La declaración igualmente invita y en cierta medida obliga a los Estados a tomar medidas efectivas de carácter legislativo, administrativo, judicial o de otra índole para prevenir y terminar con las desapariciones forzadas. ${ }^{35}$

Asimismo, el artículo 4o. de la Declaración estipula la obligación de tipificar el delito de desaparición forzada en las leyes nacionales; ${ }^{36}$ igualmente, prohíbe que este tipo de crímenes sean ejecutados incluso en estado de guerra o de emergencia, ${ }^{37}$ estableciendo la ilegalidad de cualquier excluyente de responsabilidad basada en la obediencia debida. ${ }^{38}$

31 A pesar de la oposición durante los Travaux preparatoires, la mayoría de los Estados, incluyendo Austria, Alemania y México, con el apoyo de Argentina y Chile lucharon para que se catalogara a este crimen como una especial y particular ofensa en contra de la humanidad. Al final, la Declaración y la Convención Interamericana sobre Desaparición Forzada de Personas sólo incluyen esta categoría en sus preámbulos. Véase Brody, Reed y González, Felipe, op. cit., p. 382 .

32 Declaración sobre la protección de todas las personas contra las desapariciones forzadas de las Naciones Unidas, artículo 1.1.

33 Idem.

34 Ibidem, artículo 1.2.

35 Declaración sobre la Protección de todas las Personas contra las Desapariciones Forzadas de las Naciones Unidas, artículo 30.

${ }^{36}$ General Comment on Article 4 of the UN Universal Declaration on Enforced Disappearance in U.N. Econ. \& Soc. Council [ECOSOC], Commission on Human Rights, Working Group on Enforced or Involuntary Disappearances: Annual Report on Civil and political rights including the questions of: Disappearances and Summary Executions. UN Doc. E/ CN.4/1996/38 (Jan. 15, 1996).

37 Declaración sobre la protección de todas las personas contra las desapariciones forzadas de las Naciones Unidas, artículo 7o.

38 Ibidem, articulo 60. 
En su texto, la Declaración describe las medidas que los Estados deben tomar para prevenir estos actos, entre las que encontramos aquellas destinadas a proporcionar y proteger el debido proceso legal, normas ya consagradas en otras declaraciones y convenciones de las Naciones Unidas. ${ }^{39}$

Una importante contribución es la contenida en el artículo 13 de esta Declaración, que enfatiza la importancia de que se encuentre disponible un recurso efectivo cuando esta violación sea cometida ${ }^{40}$ y que este crimen sea investigado por el Estado. ${ }^{41}$

La Declaración igualmente prohíbe "privilegios, inmunidades y excepciones especiales" ${ }^{42}$ En particular, su artículo 18 declara la invalidez de "leyes de amnistía" que impidan u obstaculicen la investigación de este crimen.

En 2001 con el fin de redactar un instrumento normativo vinculante en materia de desaparición forzada de personas en el Sistema de Naciones Unidas se creó un Grupo Especial de Trabajo en el que participaron miembros de delegaciones estatales, observadores de organizaciones de la sociedad civil, entre otros. Dicho trabajo dio como resultado la "Convención Internacional para la protección de todas las personas contra las desapariciones forzadas”, la cual apenas entró en vigor el 23 de diciembre de $2010 .{ }^{43}$

\section{La Convención Interamericana sobre Desaparición Forzada de Personas}

En 1987, la Asamblea General de la Organización de Estados Americanos (OEA) solicitó a la Comisión Interamericana de Derechos Humanos

39 Ibidem, artículos 9o. a 12.

40 Ibidem, artículo 13.

${ }^{41}$ Ibidem, artículo 14.

${ }^{42}$ Ibidem, artículo 16.3.

${ }^{43}$ U.N. Econ. \& Soc. Council [ECOSOC], Commission on Human Rights, Working Group to elaborate a draft legally binding normative instrument for the protection of all persons from enforced disappearance: Report of the intersessional open-ended working group to elaborate a draft legally binding normative instrument for the protection of all persons from enforcement disappearance, 6-11, U.N. Doc. E/CN.4/2004/59 (February 23, 2004) (prepared by Mr. Bernard Kessedijian). 
que preparara un primer borrador de una Convención Interamericana sobre Desaparición Forzada de Personas. ${ }^{44}$ En 1988, previa consulta con varias organizaciones no gubernamentales, la Comisión Interamericana produjo dicho borrador. ${ }^{45}$

Posteriormente, la Comisión de Asuntos Políticos y Jurídicos del Consejo Permanente de la OEA, estableció un grupo de trabajo que pasó varios años examinando el proyecto de la Comisión Interamericana a puerta cerrada, presentando una versión preliminar a la Asamblea General de la OEA en 1992. ${ }^{46}$ En las discusiones las organizaciones no gubernamentales fueron excluidas, aunque eventualmente, sus opiniones tuvieron un impacto importante en la versión final del documento. ${ }^{47}$ Los trabajos y proclamaciones tanto de la Declaración sobre la Protección de todas las Personas contra las Desapariciones Forzadas de las Naciones Unidas como los trabajos de la Convención Interamericana sobre Desaparición Forzada de Personas fueron virtualmente procesos paralelos.

La Convención Interamericana sobre Desaparición Forzada de Personas es el primer tratado especializado y vinculante en esta materia. Esta Convención, no sólo ha ayudado a reafirmar la jurisprudencia de la Corte Interamericana de Derechos Humanos sobre el delito de desaparición forzada de personas, sino que ha ayudado a desarrollar la jurisprudencia en este tema a lo largo de los años.

Uno de los grandes logros alcanzado en la Convención Interamericana sobre Desaparición Forzada de Personas fue la definición que actualmente consta en el artículo II de dicho instrumento en donde claramente define la desaparición forzada de personas como:

La privación de la libertad a una o más personas, cualquiera que fuere su forma, cometida por agentes del Estado o por personas o grupos de personas que actúen

${ }^{44}$ Resolution Concerning 1986/87 Annual Report of the Inter-American Commission.

${ }_{45}$ Comments on Draft Inter-American Convention on Forced Disappearance of Persons, in Annual Report of the Inter-American Commission of Human Rights 1992.

${ }^{46}$ Brody, Reed y González, Felipe, op. cit., p. 375.

47 México y Uruguay estuvieron entre los países que bloquearon la iniciativa para invitar a Organizaciones no Gubernamentales para participar en los Trabajos Preparatorios de la Convención; sin embargo, Chile insistió en su participación en el proceso. Cfr. Brody, Reed y González, Felipe, op. cit., p. 375. 
con la autorización, el apoyo o la aquiescencia del Estado, seguida de la falta de información o de la negativa a reconocer dicha privación de libertad o de informar sobre el paradero de la persona, con lo cual se impide el ejercicio de los recursos legales y de las garantías procesales pertinentes.

De esta forma, la Convención Interamericana sobre Desaparición Forzada de Personas establece: la obligación de tipificar y perseguir a los perpetradores de estos actos (artículos III y VII); los principios de jurisdicción y extradición (artículos IV, V y VI); la exclusión de las jurisdicciones militares (artículo IX); la absoluta prohibición de derogación (artículo X) y los principios básicos para monitorear la conducta de los Estados parte (artículos XIII).

Los trabajos, ideas y principios de la Convención Interamericana sobre Desaparición Forzada de Personas han sido, a su vez, retomados en otros instrumentos internacionales, como es el Estatuto de Roma que incluye este crimen en su artículo $70 .^{48}$

La influencia de la Comisión Interamericana de Derechos Humanos en Latinoamérica ha sido, desde su creación, un pilar para el mejoramiento de los estándares de derechos humanos y democracia en los países del continente. ${ }^{49}$

A la par de la Comisión Interamericana, el Sistema Interamericano ha sido complementado por la jurisprudencia de la Corte Interamericana de Derechos Humanos. En sus más de 30 años de funcionamiento la Corte ha cambiado el rol tradicional del derecho internacional en el continente, estableciendo un nuevo estándar en materia de responsabilidad internacional cuando han sido cometidas violaciones a los derechos humanos. ${ }^{50}$

48 Estatuto de la Corte Penal Internacional (Estatuto de Roma), 17 de julio de 1998 U.N. Doc. A/Conf. 183/9, artículo 7o.

49 Véase, por ejemplo, Bicudo, Helio, The Inter-American Commission on Human Rights and the Process of Democratization in Peru, Human Rights. Brief, núm. 9, p. 18.

50 Véase, por ejemplo, Cançado Trindade, Antonio Augusto, "The Case-Law of the InterAmerican Court of Human Rights: An Overview", Studi di Diritto Internazionale in Onore di Gaetano Arangio-Ruiz, vol. III, Napoli, 2004. 
El primer caso contencioso decidido en su etapa de fondo por la Corte fue el ya célebre caso Velásquez Rodríguez. ${ }^{51}$ Desde entonces, la Corte creó su propia teoría respecto a la desaparición forzada de personas. Más aun se puede afirmar que la jurisprudencia de la Corte Interamericana de Derechos Humanos muestra la evolución del marco legal internacional en este campo, y a su vez, ha inspirado diversas decisiones tanto a nivel local como internacional, como es el caso de la Corte Europea de Derechos Humanos. ${ }^{52}$

En Velásquez Rodríguez la Corte Interamericana de Derechos $\mathrm{Hu}$ manos encontró un patrón de violaciones procesales que incluyeron la desaparición de Manfredo Ángel Velásquez Rodríguez. Este patrón consistía en el secuestro ${ }^{53}$ de personas que eran usualmente consideradas peligrosas a raíz de sus actividades políticas, ${ }^{54}$ utilizando el ejército y la policía para conducirlos a centros de detención ilegales y clandestinos. ${ }^{55}$ Estas detenciones eran seguidas de la negación sistemática de cualquier conocimiento de la detención o del destino de las víctimas. ${ }^{56}$

La Corte en su sentencia concluyó que Honduras no sólo era responsable de la detención sino también de la falta de una protección judicial adecuada, cuando el gobierno no previno, investigó y eventualmente castigó a los responsables de esos actos. ${ }^{57}$ Para la Corte Interamericana una investigación no podía calificarse como efectiva si la misma no producía resultados concretos o al menos demostraba que había un genuino interés en descubrir la verdad. En este caso concreto, la Corte encontró que la investigación "era una mera formalidad destinada al fracaso". ${ }^{58}$

51 Corte IDH, Caso Velásquez Rodríguez vs. Honduras, Fondo, sentencia del 29 de julio de 1988, Serie C, núm. 4.

52 Singh Sethi, Gobind, The European Court of Human Rights' Jurisprudence on Issues of Forced Disappearances, Human Rights Brief, núm. 8, 2001, p. 29 y Taqi, Irum, Note:Adjudicating Disappearance cases in Turkey: An Argument for Adopting the Inter-American Court of Human Rights' Approach, 24 Fordham International Law Journal, núm. 24, 2001, p. 940.

53 Corte IDH, Caso Velásquez Rodríguez vs. Honduras, Fondo, sentencia del 29 de julio de 1988, Serie C, núm. 4, párr. 147 (b).

54 Ibidem, párr. 147(d) (i).

55 Ibidem, párr. $147 \mathrm{~d}$ (iii).

56 Ibidem, párr. 147 (d)(iv).

57 Ibidem, párr. $147(\mathrm{~d})(\mathrm{v})$.

58 Ibidem, párr. 177. 
En esta lógica, surgió la pregunta de ¿cómo es posible probar la desaparición forzada de personas en un foro como la Corte Interamericana de Derechos Humanos? La Corte estableció un test de dos pasos para determinar el estándar probatorio en casos de este tipo. Primero, basado en los hechos, es necesario demostrar la existencia de una práctica reiterada, y en segundo lugar, una vez que la existencia de esta práctica extendida ha sido demostrada, es necesario que la misma tenga correspondencia con el caso concreto para determinar si el modus operandi corresponde. ${ }^{59}$ Cuando se han podido cumplir con estos requerimientos, el Estado demandado lleva la carga de la prueba. ${ }^{60}$

En el caso Velásquez Rodríguez, la Corte encontró que el Estado hondureño había violado de forma continuada, en perjuicio de la víctima, sus derechos consagrados en la Convención Americana sobre Derechos Humanos en cuanto a la liber tad personal (artículo 7o.), a la integridad personal (artículo 5o.), al derecho a la vida (artículo 4o.) violando, consecuentemente, su obligación general de respetar a los derechos (artículo 1o.). ${ }^{61}$

Desde Velásquez Rodríguez la Corte Interamericana de Derechos Humanos ha dictado sentencias condenatorias en decenas de casos relacionados con la desaparición forzada de personas en diversos países del continente. Asimismo, la Corte Interamericana ha considerado la desaparición forzada de personas como una violación pluriofensiva, es decir, se ha reconocido que en su ejecución afecta una gran cantidad de derechos tanto de la víctima directa como de sus familiares. De ahí que en los últimos años se haya verificado en la jurisprudencia de la Corte IDH una expansión en la visión de los derechos que son vulnerados a partir de dicho crimen de lesa humanidad.

\section{EL PROCESO DE INCORPORACIÓN DE LOS ESTÁNDARES} INTERNACIONALES EN MATERIA DE DESAPARICIÓN FORZADA EN MÉXICO

59 Ibidem, párr. 126.

${ }^{60}$ Ibidem, párr. 124.

${ }^{61}$ Ibidem, párr. XIV. Una visión por demás pertinente de los primeros avances de la comunidad internacional y de la Corte IDH en materia de desaparición forzada de personas sobre la misma temática tratada en este apartado se puede encontrar en: Parayre, Sonia, "La desaparición forzada de personas como violación continuada de los derechos humanos y su incidencia en la determinación de la competencia Ratione Temporis de la Corte Interamericana de Derechos Humanos", Revista IIDH, vol 29, pp. 25 y ss. 
El proceso de incorporación de normas de derecho internacional puede ser dividido en tres etapas: la social, la política y la legal. ${ }^{62}$ En México, la desaparición de un gran número de perseguidos políticos, en especial, en 1968 y a lo largo de la denominada "guerra sucia" marcó un hito en la historia moderna del país que eventualmente impulsaría procesos transnacionales de recepción del derecho internacional en el ámbito nacional.

La incorporación de los estándares internacionales en materia de desaparición forzada ha sido gradual, desde el año 2000 en el que se tipificó el delito en el Código Penal Federal hasta 2001, en el que el Senado de la República ratificó la Convención Interamericana sobre Desaparición Forzada de Personas. Estos dos procesos, en este orden en particular, no estuvieron exentos de controversias, como se describirá a continuación.

\section{El proceso legislativo de tipificación del delito de desaparición forzada de personas en el Código Penal Federal}

El primer paso en la incorporación de los estándares internacionales en materia de desaparición forzada en México se dio con la inclusión del tipo penal de este delito en el Código Penal Federal.

La iniciativa fue promovida por diputados del grupo parlamentario del Partido de la Revolución Democrática. ${ }^{63}$ El proyecto original, cabe decir, era mucho más rico y preciso respecto a varios aspectos de suma importancia. Dicha iniciativa incluía la imprescriptibilidad del delito de desaparición forzada de personas y su estatus como crimen de lesa humanidad. Asimismo, se estipulaba la improcedencia de invocar la cadena

62 Carrillo, Arturo J., "Bringing International Law Home: The Innovative role of Human Rights Clinics in the Transnational Legal Process”, Columbia Human Rights Law Review, núm. 35, 2003-2004, p. 536.

63 Exposición de Motivos. Iniciativa de Reformas al Código Penal Federal, al Código Federal de Procedimientos Penales y a la Ley de Amparo (para tipificar la desaparición forzada de personas como un ilícito penal, con la finalidad de fortalecer los instrumentos jurídicos para vivir en un verdadero Estado de derecho). Cámara de Diputados LVIII Legislatura, 12 de septiembre de 2000 . 
de mando como excluyente de responsabilidad. Desafortunadamente, este proyecto siempre restringió la autoría del delito a agentes estatales. En adición a la tipificación del delito se propuso una enmienda al segundo párrafo de la fracción X del artículo 73 de la Ley de Amparo para posibilitar la protección de la justicia federal en aquellos casos en que se trata de convalidar una detención que en principio es ilegal. ${ }^{64}$

Posteriormente, la propuesta original fue modificada por la Comisión de Derechos Humanos y Justicia de la Cámara de Diputados, eliminando su estatus como crimen de lesa humanidad. La Comisión igualmente permitió que este delito se rigiera por la normatividad ordinaria que permite que un delito prescriba y en ningún momento se consideró incluir expresamente como autor del delito a particulares que pudiesen llegar a actuar con la autorización, el apoyo o aquiescencia del Estado. ${ }^{65}$

64 Idem.

65 Comisión de Justicia y Derechos Humanos. Iniciativa de Reformas al Código Penal Federal y al Código Federal de Procedimientos Penales. Cámara de Diputados LVIII Legislatura, 20 de diciembre de 2000.

Código Penal Federal Capítulo III bis, Desaparición forzada de personas.

Artículo 215-A.- Comete el delito de desaparición forzada de personas, el servidor público que, independientemente de que haya participado en la detención legal o ilegal de una o varias personas, propicie o mantenga dolosamente su ocultamiento bajo cualquier forma de detención.

Artículo 215-B. - A quien cometa el delito de desaparición forzada de personas se le impondrá una pena de cinco a cuarenta años de prisión.

Si la víctima fuere liberada espontáneamente dentro de los tres días siguientes a su detención la pena será de ocho meses a cuatro años de prisión, sin perjuicio de aplicar la que corresponda a actos ejecutados u omitidos que constituyan por sí mismos delitos.

Si la liberación ocurriera dentro de los diez días siguientes a su detención, la pena aplicable será de dos a ocho años de prisión, sin perjuicio de aplicar la que corresponda a actos ejecutados u omitidos que constituyan por sí mismo delitos.

Estas penas podrán ser disminuidas hasta una tercera parte en beneficio de aquel que hubiere participado en la comisión del delito, cuando suministre información que permita esclarecer los hechos, y hasta en una mitad, cuando contribuya a lograr la aparición con vida de la víctima.

Artículo 215-C. - Al servidor Público que haya sido condenado por el delito de desaparición forzada de personas, además se le destituirá del cargo y se le inhabilitará de uno a veinte años para desempeñar cualquier cargo, comisión o empleo públicos.

Artículo 215-D. - La oposición o negativa a la autoridad competente para tener libre e inmediato acceso al lugar donde haya motivos para creer que se pueda encontrar a una persona desaparecida, por parte del servidor público responsable del mismo, será sancionada con la 
La Comisión de Derechos Humanos y Justicia consideró oportuno desechar el carácter imprescriptible de este delito, por considerar que "la idea de establecer la existencia de penas y delitos imprescriptibles, [no es] propi[a] de un Estado de Derecho-Democrático, sino más bien de sistemas dictatoriales"; sin embargo, se olvidó que la imprescriptibilidad del delito de desaparición forzada busca, precisamente, evitar la impunidad de actos atroces cometidos por sistemas dictatoriales.

En cuanto a la prohibición de que el delito de desaparición forzada de personas fuera objeto de amnistía o indulto, la Comisión estimó que ello resultaba "inconveniente" para determinados casos, toda vez que por motivos políticos o sociales, dichos instrumentos jurídicos "podían ser utilizados con fines de estabilidad o paz social”. Al respecto, cabe recordar que en marzo de 2001 la Corte Interamericana de Derechos Humanos estableció criterios específicos que prohíben la existencia de amnistías en casos de delitos de lesa humanidad por lo que la consideración de la Comisión de Derechos Humanos y Justicia resulta contraria a lo estipulado por ese tribunal internacional. ${ }^{66}$

Dentro de las discusiones en la Cámara de Diputados surgió el tema relacionado con posibles modificaciones a la Ley de Amparo con el fin de adecuar esta institución a las características propias del delito de desaparición forzada de personas. Respecto a esto, la Comisión de Justicia y Derechos Humanos mencionó, sin muchos argumentos que "no era pertinente [ya] que era necesario realizar un análisis y estudio mucho más sereno y reflexivo sobre dicha propuesta”. Y argumentó, que dicha reforma "deber[ía] dejarse para ser considerada dentro de la reforma

destitución de su cargo, comisión o empleo, sin perjuicio de la aplicación de las penas de los demás delitos en que pudiera incurrir con motivo de su conducta.

${ }^{66}$ Véanse, por ejemplo, los siguientes casos: Corte IDH, Caso Barrios Altos vs. Perú, Fondo, sentencia del 14 de marzo de 2001, Serie C, núm. 75. El mismo criterio ha sido reiterado en Corte IDH, Caso La Cantuta vs. Perú, Fondo, Reparaciones y Costas, sentencia del 29 de noviembre de 2006, Serie C, núm. 162, y Corte IDH, Caso Almonacid Arellano y otros vs. Chile, Excepciones Preliminares, Fondo, Reparaciones y Costas, sentencia del 26 de septiembre de 2006, Serie C, núm. 154; Corte IDH, Caso Gomes Lund y otros (Guerrilha do Araguaia) vs. Brasil, Excepciones Preliminares, Fondo, Reparaciones y Costas, sentencia del 24 de noviembre de 2010, Serie C, núm. 219 y Corte IDH, Caso Gelman Vs. Uruguay, Fondo y Reparaciones, sentencia del 24 de febrero de 2011, Serie C, núm. 221. 
integral, que [terminaría en] una nueva ley de Amparo". ${ }^{67}$ Todo esto en torno a una discusión que se tenía en aquella época y que ha ido evolucionando a través de los años. ${ }^{68}$

En cuanto a este proceso, cabe destacar que en ningún momento los debates giraron en torno a si esta legislación era o no compatible con los estándares internacionales en materia de desapariciones forzadas, lo cual, a la postre impidió que la legislación aprobada tuviera un enfoque de derecho internacional de los derechos humanos.

Este proyecto eventualmente fue aprobado el 21 de diciembre de 2000 por 458 votos a favor y ningún voto en contra en la Cámara de Diputados. Posteriormente, el 25 de abril de 2001, el Senado de la República aprobó el proyecto con 83 votos a favor y ninguna objeción. ${ }^{69}$ Si bien, por el momento la discusión legislativa había concluido, las decisiones tomadas por el Poder Legislativo Federal serían objeto de revisión por tribunales tanto a nivel nacional como internacional, en particular, por la Corte Interamericana de Derechos Humanos en el caso Rosendo Radilla Pacheco.

67 Comisión de Justicia y Derechos Humanos. Iniciativa de Reformas al Código Penal Federal y al Código Federal de Procedimientos Penales. Cámara de Diputados LVIII Legislatura, 20 de diciembre de 2000.

68 A principios de siglo, hablar de una "Nueva Ley de Amparo" era un tema en boga a partir del proyecto presentado por jueces de la Suprema Corte de Justicia de la Nación en conjunto con juristas destacados entre los que se encontraban Héctor Fix-Zamudio, José Ramón Cossío Díaz y Arturo Zaldívar (los últimos dos eventualmente fueron nombrados ministros de la Suprema Corte posteriormente). El proyecto desafortunadamente nunca trascendió del ámbito académico a pesar de haber sido ampliamente difundido y discutido. Cfr. varios autores, Proyecto de Ley de Amparo Reglamentaria de los Artículos 103 y 107 de la Constitución Política de los Estados Unidos Mexicanos, México, Suprema Corte de Justicia de la Nación, 2000, 254 pp. No obstante el fracaso legislativo del proyecto, la discusión motivada desde entonces ha rendido sus frutos, ya que a partir de la reforma constitucional de junio de 2011 se ha dado lugar a que el juicio de amparo proceda por normas generales, actos u omisiones de la autoridad que violen derechos humanos, lo que ha abierto una la Décima Época en la jurisprudencia del Poder Judicial de la Federación. Cfr. Suprema Corte de Justicia de la Nación. Acuerdo General Número 9/2011 del Pleno por el que se determina el inicio de la Décima Época del Semanario Judicial de la Federación, 29 de agosto de 2011.

${ }^{69}$ Decreto por el que se reforman y adicionan diversas disposiciones del Código Penal Federal y del Código Federal de Procedimientos Penales, Dictamen de primera lectura, LVIII Legislatura, Año I, Segundo Periodo Ordinario, Diario 13, 25 de abril de 2001. 


\section{El proceso de ratificación de la Convención Interamericana sobre Desaparición Forzada de Personas.}

La Convención Interamericana sobre Desaparición Forzada de Personas fue firmada por el Ejecutivo Federal el 4 de mayo de 2001 y posteriormente fue discutida y votada por el Senado de la República en sesión del 10 de diciembre de 2001, la ratificación fue depositada ante la Organización de Estados Americanos el 9 de abril de 2002. Este proceso se desarrolló después de la tipificación del crimen de desaparición forzada en el Código Penal Federal, como se describió anteriormente, sin que se considerara pertinente modificar algún otro tipo de legislación a nivel federal. El proceso de ratificación se realizó en el Senado en las sesiones del 18 de septiembre de $2001^{70}$ y 10 de diciembre de $2001 .{ }^{71}$ Durante la segunda sesión, el Senado también votó la ratificación a la Convención sobre la Imprescriptibilidad de los Crímenes de Guerra y de los Crímenes de Lesa Humanidad. ${ }^{72}$

Las discusiones se enfocaron en tres temas principales: primero, las medidas legislativas adicionales que requiere la Convención en cuanto a la tipificación del delito de desaparición forzada de personas en la legislación nacional; en segundo lugar, se discutió la imprescriptibilidad de este crimen, y finalmente, se discutió la inclusión de una reserva en lo concerniente a la justicia militar. ${ }^{73}$

${ }^{70}$ Senado de la República. Convención Interamericana sobre Desaparición Forzada de Personas, Adoptada en la ciudad de Belem, Brasil, el 9 de junio de 1994, Dictamen de primera lectura, LVIII Legislatura, Año II, Primer Periodo Ordinario, Diario 32, 18 de septiembre de 2001.

${ }^{71}$ Senado de la República. Convención Interamericana sobre Desaparición Forzada de Personas, Adoptada en la ciudad de Belem, Brasil, el 9 de junio de 1994, Dictamen de segunda lectura, LVIII Legislatura, Año II, Primer Periodo Ordinario, Diario 33, 10 de diciembre de 2001 .

72 Senado de la República. Convención sobre la Imprescriptibilidad de los Crímenes de Guerra y de los Crímenes de Lesa Humanidad, adoptada por la Asamblea General de las Naciones Unidas, el 26 de noviembre de 1968. Dictamen de segunda lectura, LVIII Legislatura, Año II, Primer Periodo Ordinario, Diario 33, 10 de diciembre de 2001.

73 Véanse en especial los debates del Senado en la sesión de 10 de Diciembre de 2001 en: Senado de la República. Convención Interamericana sobre Desaparición Forzada de Personas, Adoptada en la ciudad de Belem, Brasil, el 9 de junio de 1994, Dictamen de segunda lectura, LVIII Legislatura, Año II, Primer Periodo Ordinario, Diario 33, 10 de diciembre de 2001. 
El artículo I(d) de la Convención Interamericana sobre Desaparición Forzada de Personas obliga a las partes a "[t]omar las medidas de carácter legislativo, administrativo, judicial o de cualquier otra índole necesarias para cumplir con los compromisos asumidos en la... Convención”. Entre esos deberes destaca el de tipificar y sancionar esta conducta en la legislación interna. ${ }^{74} \mathrm{Al}$ respecto, y considerando las modificaciones al Código Penal Federal que se describieron en el apartado anterior, el Senado de la República no consideró necesario realizar cambios adicionales. ${ }^{75}$

Sin embargo, la Convención Interamericana sobre Desaparición Forzada de Personas menciona que este crimen puede ser perpetrado "por personas o grupos de personas que actúen con la autorización, el apoyo o la aquiescencia del Estado". ${ }^{76}$ El delito tal y como se encuentra tipificado no respeta los estándares de esta Convención ya que sólo prevé como sujeto activo la participación de servidores públicos, es decir, agentes estatales. Esto provoca que sea imposible perseguir penalmente a particulares que eventualmente llegasen a actuar con la tolerancia del Estado. Igualmente, no se incluyó el elemento de la descripción del tipo relacionado con los obstáculos para ejercer los recursos legales y las garantías procesales pertinentes. Sin embargo, a pesar de estas obviedades, el Senado no encontró ningún conflicto entre el artículo 215-A del Código Penal Federal y el artículo II de la Convención Interamericana sobre Desaparición Forzada de Personas. ${ }^{77}$

${ }^{74}$ La Convención Interamericana sobre Desaparición Forzada de Personas en su artículo III dispone que "Los Estados partes se comprometen a adoptar, con arreglo a sus procedimientos constitucionales, las medidas legislativas que fueren necesarias para tipificar como delito la desaparición forzada de personas, y a imponerle una pena apropiada que tenga en cuenta su extrema gravedad. Dicho delito será considerado como continuado o permanente mientras no se establezca el destino o paradero de la víctima...”.

75 En general, todos los senadores coincidieron en esto desde la primera sesión. Véase por ejemplo, el dictamen de las Comisiones Unidas de Relaciones Exteriores, Organismos Internacionales y de Justicia, Convención Interamericana sobre Desaparición Forzada de Personas, adoptada en la ciudad de Belem, Brasil, el 9 de junio de 1994, Dictamen de primera lectura, LVIII Legislatura, Año II, Primer Periodo Ordinario, Diario 32, 18 de septiembre de 2001.

${ }^{76}$ La Convención Interamericana sobre Desaparición Forzada de Personas en su artículo II.

77 Senado de la República. Comisiones Unidas de Relaciones Exteriores, Organismos Internacionales y de Justicia, Convención Interamericana sobre Desaparición Forzada de Personas, Adoptada en la ciudad de Belem, Brasil, el 9 de junio de 1994, Dictamen de primera 
Sobre la imprescriptibilidad del delito de desaparición forzada, se pueden encontrar serias discrepancias entre lo que se debatió y discutió, y lo que finalmente se aprobó en la ratificación de la Convención sobre la Imprescriptibilidad de los Crímenes de Guerra y de los Crímenes de Lesa Humanidad y la Convención Interamericana sobre Desaparición Forzada de Personas.

Por una parte, el Senado nunca se planteó la posibilidad de que el delito prescribiera. Incluso, se llegó a señalar que las disposiciones de la Convención Interamericana sobre Desaparición Forzada de Personas derogarían "implícitamente" cualquier disposición penal que hiciera prescriptible este delito. ${ }^{78}$ Sin embargo, la discusión y ratificación de la Convención sobre la Imprescriptibilidad de los Crímenes de Guerra y de los Crímenes de Lesa Humanidad, motivó que el Senado aprobara una declaración interpretativa con la intención de considerar impres-

lectura, LVIII Legislatura, Año II, Primer Periodo Ordinario, Diario 32, 18 de septiembre de 2001, "Cualquiera que sea su forma, la cometida por agentes del Estado o por personas o grupos de personas que actúen con autorización, el apoyo o la aquiescencia del Estado; a juicio nuestro, no se manifiesta contradicción alguna, en la especie. En efecto, si analizamos comparativamente los supuestos y las disposiciones que obran inmersos en ambos preceptos, y los aplicamos a cualquiera de los casos que tales hipótesis prevén, no es difícil establecer que en la consumación del delito necesariamente debe concurrir la participación de un servidor público o de sujetos que tengan esta calidad”.

78 Respecto a la imprescriptibilidad de este delito se mencionó que "Por consiguiente, la aprobación de tal instrumento no provocaría la existencia de un problema de contradicción con las disposiciones del Código Penal Federal, habida cuenta que estaríamos en un caso de derogación implícita, que haría imposible la validez en forma simultánea de las reglas de la prescripción previstas en el Capítulo VI, del Título Quinto, Libro Primero, del ordenamiento jurídico en cita, tratándose del delito de desaparición forzada de personas. Esta consideración es dable sustentarlas, además, en el artículo $6^{\circ}$ del propio cuerpo normativo, al disponer que: "Cuando se cometa un delito no previsto en este Código, pero sí en una ley especial o en un tratado internacional de observancia obligatoria en México, se aplicarán éstos, tomando en cuenta las disposiciones del Libro Primero del presente Código y, en su caso, las conducentes del Libro Segundo. Cuando una misma materia aparezca regulada por diversas disposiciones, la especial prevalecerá sobre la general”. Y los tratados internacionales se consideran como leyes especiales". Véase Comisiones Unidas de Relaciones Exteriores, Organismos Internacionales y de Justicia. Convención Interamericana sobre Desaparición Forzada de Personas, Adoptada en la ciudad de Belem, Brasil, el 9 de junio de 1994, Dictamen de segunda lectura, LVIII Legislatura, Año II, Primer Periodo Ordinario, Diario 33, 10 de diciembre de 2001. 
criptibles únicamente los crímenes que consagra la Convención, cometidos con posterioridad a su entrada en vigor. ${ }^{79}$

En cuanto a la Convención Interamericana sobre Desaparición Forzada de Personas el Senado aprobó una declaración interpretativa que tuvo la intención de que dicho instrumento internacional fuera aplicable únicamente "a los hechos que constituy[eran] desaparición forzada de personas, [que] se ordenen, ejecuten o cometan con posteridad a la entrada en vigor de la... Convención”. Dicha declaración interpretativa no se encontró fuera de controversia, en opinión de al menos uno de los senadores, esta declaración tenía la intención de constituirse en los hechos en un tipo de reserva incompatible con el objeto y fin del tratado. ${ }^{80}$

Cabe también señalar que el Senado incluyó una reserva para mantener la jurisdicción militar en casos de desaparición forzada, en oposición al artículo IX de la Convención Interamericana sobre Desaparición Forzada de Personas. Dicho artículo señala que "[l]os presuntos responsables de los hechos constitutivos del delito de desaparición forzada de personas sólo podrán ser juzgados por las jurisdicciones de derecho común competentes en cada Estado, con exclusión de toda jurisdicción

79 Dicha declaración interpretativa textualmente señala que "Con fundamento en el artículo 14 de la Constitución Política de los Estados Unidos Mexicanos, el Gobierno de México, al ratificar la Convención sobre la Imprescriptibilidad de los Crímenes de Guerra y de los Crímenes de Lesa Humanidad, adoptada por la Asamblea General de las Naciones Unidas el 26 de noviembre de 1968, entenderá que únicamente considerará imprescriptibles los crímenes que consagra la Convención, cometidos con posterioridad a su entrada en vigor para México." Senado de la República. Convención sobre la Imprescriptibilidad de los Crímenes de Guerra y de los Crímenes de Lesa Humanidad, adoptada por la Asamblea General de las Naciones Unidas, el 26 de noviembre de 1968. Dictamen de segunda lectura, LVIII Legislatura, Año II, Primer Periodo Ordinario, Diario 33, 10 de diciembre de 2001.

${ }^{80}$ Respecto a la declaración interpretativa un miembro del Senado mencionó que "tal declaración interpretativa es prácticamente una reserva.Y si partimos de que la formulación de reservas es válida, siempre que éstas no sean incompatibles con el objeto y propósito del instrumento en cuestión y versen sobre una o más disposiciones específicas, no daremos cuenta de que la declaración interpretativa, que el gobierno mexicano mantiene en este caso, altera completamente la naturaleza de la Convención y evidencia la falta de voluntad del gobierno mexicano para asumir compromisos concretos en la materia”, en Senado de la República, Convención Interamericana sobre Desaparición Forzada de Personas, adoptada en la ciudad de Belem, Brasil, el 9 de junio de 1994, Dictamen de segunda lectura, LVIII Legislatura, Año II, Primer Periodo Ordinario, Diario 33, 10 de diciembre de 2001. 
especial, en particular la militar”. Además señala que "[l]os hechos constitutivos de la desaparición forzada no podrán considerarse como cometidos en el ejercicio de las funciones militares". Y finalmente destaca que "[n]o se admitirán privilegios, inmunidades, ni dispensas especiales en tales procesos, sin perjuicio de las disposiciones que figuran en la Convención de Viena sobre Relaciones Diplomáticas”.

En respuesta, el Senado formuló una reserva expresa al artículo IX argumentando que "la Constitución Política reconoce el fuero de guerra, cuando el militar haya cometido algún ilícito encontrándose en servicio." La reserva va en el sentido de afirmar que

[E]l fuero de guerra no constituye jurisdicción especial en el sentido de la Convención, toda vez que conforme al articulo 14 de la Constitución mexicana nadie podrá ser privado de la vida, de la libertad o de sus propiedades, posesiones o derechos, sino mediante juicio seguido ante los tribunales previamente establecidos, en el que se cumplan las formalidades esenciales del procedimiento y conforme a las leyes expedidas con anterioridad al hecho.

Este tema prácticamente no fue discutido en los debates parlamentarios y esta reserva es única en su tipo en el continente. La única consideración realizada al efecto fue el sentido de mencionar que "el fuero militar es ordinario, de tal suerte que no hay tribunal especial, como lo establece el Apartado Noveno de la Convención, ni estamos en el supuesto del artículo 13 de la Constitución Federal". ${ }^{81}$ De esta afirmación, se puede deducir que los senadores interpretaron el lenguaje de la Convención Interamericana sobre Desaparición Forzada de Personas desde una concepción interna, utilizando conceptos y estándares del derecho mexicano, y no de derecho internacional. Al respecto, para efectos del derecho internacional, la jurisdicción militar es una jurisdicción especial y de aquí partirían los argumentos de la Corte Interamericana para declarar la invalidez de esta reserva, como se verá más adelante.

81 Senado de la República. Convención Interamericana sobre Desaparición Forzada de Personas, Adoptada en la ciudad de Belem, Brasil, el 9 de junio de 1994, Dictamen de segunda lectura, LVIII Legislatura, Año II, Primer Periodo Ordinario, Diario 33, 10 de diciembre de 2001 . 
Dentro del marco del deseo de poner al día al país en materia de derechos humanos, al menos normativamente hablando, se debe mencionar que a pesar de la diversidad de enfoques respecto a los temas antes aludidos; en el Senado en todo momento se destacó la necesidad y la importancia de ratificar ambos tratados. Dentro de las razones expuestas durante el debate de la aprobación de los mismos se hizo hincapié en la importancia de sumarse a la tendencia de la sociedad internacional en el fortalecimiento del sistema institucional de protección a los derechos humanos. ${ }^{82}$ Asimismo, se mencionó que la ratificación de estos tratados tenía la finalidad de contar con una mayor y mejor cooperación internacional, ${ }^{83}$ así como contribuir con la paz y la seguridad internacional ${ }^{84}$ y la necesidad de armonizar los principios que integran el sistema jurídico nacional con los que conducen las relaciones de la sociedad internacional. ${ }^{85}$

Si bien existieron poderosas razones a nivel político tanto internas como externas para ratificar dichos tratados, también se encontraron reticencias a que los mismos fueran aceptados de forma integral.

Por una parte, existe la posibilidad de que las consideraciones del Senado respecto a la declaración interpretativa y la reserva formuladas a la Convención Interamericana sobre Desaparición Forzada de Personas puedan haberse fundamentado en el desconocimiento del derecho internacional y consecuentemente, del carácter continuado de la concepción de delito de desaparición forzada de personas. Muestra de ello es la inexistencia de un debate desde el derecho internacional respecto a las declaraciones interpretativas y de la reserva formulada en los tratados comentados. En cualquier caso, el no haber vislumbrado en ese entonces la posibilidad de que esa reserva y declaración interpretativa

82 Senado de la República. Convención sobre la Imprescriptibilidad de los Crímenes de Guerra y de los Crímenes de Lesa Humanidad, adoptada por la Asamblea General de las Naciones Unidas, el 26 de noviembre de 1968. Dictamen de segunda lectura, LVIII Legislatura, Año II, Primer Periodo Ordinario, Diario 33, 10 de Diciembre de 2001.

${ }^{83}$ Senado de la República. Convención Interamericana sobre Desaparición Forzada de Personas, Adoptada en la ciudad de Belem, Brasil, El 9 de Junio de 1994, Dictamen de segunda lectura, LVIII Legislatura, Año II, Primer Periodo Ordinario, Diario 33, 10 de Diciembre de 2001 .

${ }^{84}$ Idem.

85 Idem. 
fueran declaradas invalidas conforme a los estándares del sistema interamericano de derechos humanos, permitió que dichas convenciones fueran ratificadas por todas las fuerzas políticas del país, lo cual les dio en su momento, políticamente, una mayor legitimidad.

Sin embargo, es más plausible suponer que políticamente fuera conveniente o deseable contemplar la posibilidad de que tanto la legislación penal que fue adoptada, como los tratados internacionales que estaban siendo ratificados, no pudieran ser utilizados, eventualmente, para perseguir penalmente a implicados en crímenes perpetrados en el pasado, como es el caso de los crímenes cometidos durante la llamada "guerra sucia”. Esta situación probablemente fue un aliciente para que la ratificación de estos tratados virtualmente no encontrara oposición de ninguna bancada política. ${ }^{86}$ Asimismo, resultó por demás conveniente y no encontró ningún tipo de oposición el preservar el fuero militar en toda su extensión.

De esta forma, la Convención Interamericana sobre Desaparición Forzada de Personas y la Convención sobre la Imprescriptibilidad de los Crímenes de Guerra y de los Crímenes de Lesa Humanidad fueron ratificadas simultáneamente por 91 votos a favor en el Senado el 10 de diciembre de 2001.

Los procesos de reforma al Código Penal Federal y la ratificación de la Convención Interamericana sobre Desaparición Forzada de Personas en ese orden en particular tuvieron consecuencias positivas y negativas. Por una parte, las reformas legislativas al Código Penal Federal si bien no contemplaron todos los requerimientos que imponía el derecho internacional de los derechos humanos en materia de desaparición forzada de personas, definitivamente facilitaron el proceso de ratificación de la Convención Interamericana en la materia, ya que se consideró que en el régimen jurídico interno ya se habían realizado las modificaciones

\footnotetext{
${ }^{86}$ Es relevante destacar, que un grupo parlamentario mencionó la posibilidad de la existencia de este tipo de intereses. Senado de la República, Convención Interamericana sobre Desaparición Forzada de Personas, adoptada en la ciudad de Belem, Brasil, el 9 de junio de 1994, Dictamen de segunda lectura, LVIII Legislatura, Año II, Primer Periodo Ordinario, Diario 33, 10 de diciembre de 2001. En el debate se mencionó que "la aprobación de estos instrumentos internacionales, no eximen al gobierno del presidente Fox, en esclarecer las desapariciones de ciudadanos y ciudadanas mexicanos, llevadas a cabo durante las décadas de los años sesenta, setenta, ochenta y noventa”.
} 
legislativas pertinentes, por lo que, en apariencia, no existía ninguna incompatibilidad legal y no se estaban adquiriendo nuevas responsabilidades a nivel internacional (tal vez, al haberse advertido las discrepancias la aprobación se hubiese retrasado o incluso suspendido).

Desafortunadamente, la falta de escrutinio posterior por parte de diputados y senadores derivada de la creencia errónea de que la legislación interna no necesitaba modificaciones y la falta de control jurisdiccional en la ratificación de los tratados en México propició que la legislación interna no fuera, ni sea aún compatible en su totalidad con los requerimientos de la Convención Interamericana sobre Desaparición Forzada de Personas.

\section{La Controversia Constitucional 33/2002}

A pesar de no existir en México un procedimiento de revisión abstracta respecto a la compatibilidad de los tratados internacionales con el orden jurídico interno, en el procedimiento de revisión constitucional abstracto denominado controversia constitucional se cuestionó la validez de la reserva y de la declaración interpretativa formulada por el Estado mexicano a la Convención Interamericana sobre Desaparición Forzada de Personas. Dicha controversia constitucional, a la que se le asignó el número 33/2002, fue promovida por el que era entonces jefe de gobierno de la Ciudad de México en 2002 ante la Suprema Corte de Justicia de la Nación.

En cuanto a la reserva formulada por el Estado mexicano a la Convención Interamericana sobre Desaparición Forzada de Personas la solicitud para que la misma fuera declarada inválida fue declarada improcedente por una mayoría de nueve votos ${ }^{87}$ por cuestiones procesales. En este sentido, se argumentó que dicha reserva no causaba afectación alguna al Distrito Federal, ${ }^{88}$

87 La Suprema Corte de Justicia de la Nación se encuentra conformada por once ministros. Sin embargo, para ese tiempo había una vacante y el ministro I. Ortiz Mayagoitia no participó.

${ }^{88}$ Suprema Corte de Justicia de la Nación. Desaparición fOrZada DE PERSONAS. LA RESERVA EXPRESA FORMULADA POR EL GOBIERNO MEXICANO AL ARTÍCULO IX DE LA CONVENCión Interamericana de Belém, Brasil publicada en el Diario Oficial de la Federa- 
entidad promovente de la controversia, y por ello no se estudió el fondo del asunto. ${ }^{89}$

Por el contrario, la Suprema Corte de Justicia de la Nación sí encontró causas para analizar la validez de la declaración interpretativa en virtud de los efectos que podría tener en su interpretación y aplicación del delito de "Desaparición Forzada" tipificado en el Código Penal del Distrito Federal en su artículo $168 .{ }^{90}$ El gobierno del Distrito Federal había interpuesto dicha controversia constitucional para cuestionar la

Ción el 6 de mayo de 2002, no Causa Afectación alguna al Distrito Federal, Pleno de la Suprema Corte de Justicia, Semanario Judicial de la Federación y su Gaceta, Novena Época, t. XX, septiembre de 2004, p. 1121. La Suprema Corte de Justicia de la Nación mencionó que "[l]e asiste la razón a la Cámara de Senadores al alegar la improcedencia del juicio respecto de la reserva impugnada pues, contrariamente a lo sostenido por el jefe de Gobierno del Distrito Federal en su demanda, resulta inexacto que condene a la ineficacia las distintas normas jurídicas que se han establecido en el derecho común para sancionar la conducta delictiva mencionada, en particular la establecida en el Código Penal para el Distrito Federal publicado en la Gaceta Oficial del Distrito Federal el dieciséis de julio de dos mil dos, en su artículo 168”. Véase Suprema Corte de Justicia de la Nación. Controversia Constitucional 33/2002. Jefe de gobierno del Distrito Federal. Ponente: ministro Juan Díaz Romero. Semanario Judicial de la Federación y su Gaceta, Novena Época, t. XX, agosto de 2004, p. 959.

89 Suprema Corte de Justicia de la Nación, Controversia CONSTITUCiOnal. El SObreSEIMIENTO POR FALTA DE INTERÉS LEGÍTIMO DEBE DECRETARSE SIN INVOLUCRAR EL ESTUdiO DEL FOndo, CUANdo ES EVIDENTE LA INVIABILIDAd DE LA ACCión. Pleno de la Suprema Corte de Justicia, Semanario Judicial de la Federación y su Gaceta, Novena Época, t. XX, julio de 2004, p. 920.

90 La Suprema Corte de Justicia de la Nación determinó que "Como se hizo notar en párrafos precedentes, el Código Penal para el Distrito Federal prevé y sanciona en su artículo 168 la misma conducta (desaparición forzada de personas) que el Estado mexicano, en el instrumento internacional de mérito, se comprometió a tipificar y sancionar como delito en el derecho positivo mexicano. Por tal motivo, para poder determinar si la declaración interpretativa formulada por el Gobierno de los Estados Unidos Mexicanos afecta o no las atribuciones del Distrito Federal para investigar, perseguir y sancionar la comisión del delito de desaparición forzada de personas previsto en el artículo 168 del Código Penal del Distrito Federal, es menester pronunciarse sobre temas que involucran el fondo del negocio, ya que para responder a tales cuestionamientos es necesario desentrañar el alcance de esa disposición general y verificar su constitucionalidad a la luz del principio de irretroactividad de la ley consagrado en el artículo 14 constitucional, razones más que suficientes para desestimar la invocada causa de improcedencia...”. Véase Suprema Corte de Justicia de la Nación. CONtroversia constitucional 33/2002. Jefe de Gobierno del Distrito Federal. Ponente: ministro Juan Díaz Romero, Novena Época, Semanario Judicial de la Federación y su Gaceta, t. XX, agosto de 2004, p. 959. 
validez de la declaración interpretativa formulada por México a la Convención Interamericana sobre Desaparición Forzada de Personas, ya que consideraba que la misma permitiría que los crímenes de desapariciones forzadas empezados a ejecutar antes de la firma y ratificación de dicha convención quedaran impunes.

En respuesta, la Suprema Corte de Justicia declaró la validez y constitucionalidad de la declaración interpretativa a la Convención Interamericana sobre Desaparición Forzada de Personas formulada por el Estado mexicano ya que no violaba el principio de irretroactividad de la ley penal ${ }^{91}$ reafirmando la naturaleza permanente o continua del delito de desaparición forzada de personas. ${ }^{92}$ Igualmente, la Suprema Corte decretó la imprescriptibilidad del delito de desaparición forzada de personas mientras el cuerpo de la persona desaparecida no ha sido encontrado. ${ }^{93}$ Con ello, la Suprema Corte de Justicia de la Nación rechazó la posibilidad de que los delitos de desaparición forzada de personas que se empezaron a cometer antes de la firma y ratificación de la Convención Interamericana sobre Desaparición Forzada de Personas pudieran quedar impunes, desestimando con ello la interpretación de los efectos que el gobierno del Distrito Federal le había otorgado a la declaración interpretativa, pero siguiendo el desarrollo internacional en materia de desaparición forzada, lo que dejaba al menos en el papel, sin sentido la declaración interpretativa, ${ }^{94}$ razonamiento que fue posteriormente

91 Suprema Corte de Justicia de la Nación. Desaparición fOrZada DE PERSONAS A QUE SE REFIERE La CONVENCIÓn INTERAMERICANa DE BELÉm, BRASIL, DE NUEVE DE JUNIO DE MIL NOVECIENTOS NOVENTA Y CUATRO. LA DECLARACIÓN INTERPRETATIVA FORMULADA POR EL GOBIERNO MEXICANO NO VIOLA EL PRINCIPIO DE IRRETROACTIVIDAD DE LA LEY CONSAGRADA en el artículo 14 Constitucional. Pleno de la Suprema Corte de Justicia, Semanario Judicial de la Federación y su Gaceta, Novena Época, t. XX, julio de 2004, p. 967.

92 Suprema Corte de Justicia de la Nación DESAPARICIÓn FORZADA DE PERSONAS. ESE DElito es de naturaleza Permanente o continua. Pleno de la Suprema Corte de Justicia, Semanario Judicial de la Federación y su Gaceta, Novena Época, t. XX, Julio de 2004, p. 968.

${ }^{93}$ Suprema Corte de Justicia de la Nación DESAPARICIÓN FORZADA DE PERSONAS. EL PLAZO PARA QUE OPERE SU PRESCRIPCIÓN INICIA HASTA QUE APARECE LA VÍCTIMA O SE ESTABLECE Su Destino. Pleno de la Suprema Corte de Justicia, Semanario Judicial de la Federación y su Gaceta, Novena Época, t. XX, septiembre de 2004, p. 1121.

94 Suprema Corte de Justicia de la Nación DESAPARICIÓn FORZADA DE PERSONAS. ESE DElito es de naturaleza Permanente o continua. Pleno de la Suprema Corte de Justicia, Semanario Judicial de la Federación y su Gaceta, Novena Época, t. XX, julio de 2004, p. 968. 
seguido por la Corte Interamericana de Derechos Humanos en el Caso Radilla.

Con esta decisión, los ministros de la Suprema Corte de Justicia de la Nación, lograron interpretar la declaración interpretativa formulada por el Senado a la Convención Interamericana sobre Desaparición Forzada de Personas de una forma paralela a los criterios sostenidos por la Corte Interamericana de Derechos Humanos desde el ya mencionado precedente en el caso Velásquez Rodríguez ${ }^{95}$ en el análisis del crimen de desaparición forzada de personas. ${ }^{96}$ Sin embargo, se debe señalar que para llegar a dichas conclusiones la Suprema Corte de Justicia de la Nación utilizó criterios previamente establecidos del derecho y doctrina

95 Corte IDH. Caso Velásquez Rodríguez vs. Honduras, Fondo, sentencia del 29 de julio de 1988, Serie C, núm. 4.

96 La Suprema Corte de Justicia de la Nación sostuvo que "El referido delito que contempla el artículo II de la Convención Interamericana sobre Desaparición Forzada de Personas, adoptada en la ciudad de Belém, Brasil, el día nueve de junio de mil novecientos noventa y cuatro (coincidente con lo previsto en los artículos 215-A del Código Penal Federal y 168 del Código Penal del Distrito Federal), de acuerdo con el derecho positivo mexicano, es de naturaleza permanente o continua, ya que si bien el ilícito se consuma cuando el sujeto activo priva de la libertad a una o más personas, con la autorización, apoyo o aquiescencia del Estado, seguida de la falta de información sobre su paradero, dicha consumación sigue dándose y actualizándose hasta que aparecen los sujetos pasivos o se establece cuál fue su destino”. Desaparición FORZADA DE PERSONAS. ESE DELITO ES DE NATURALEZA PERMANENTE o Continua. Pleno de la Suprema Corte de Justicia, Semanario Judicial de la Federación y su Gaceta, Novena Época, t. XX, julio de 2004, p. 968. "De conformidad con lo dispuesto por los artículos 102, fracción IV y 7o. del Código Penal Federal, tratándose de delitos permanentes o continuos, que son aquellos que se caracterizan por su consumación duradera, el plazo para la prescripción inicia a partir de que cesa su consumación. En tal orden de ideas, si el delito de desaparición forzada de personas que contempla el artículo II de la Convención Interamericana sobre Desaparición Forzada de Personas, adoptada en la ciudad de Belém, Brasil, el día nueve de junio de mil novecientos noventa y cuatro (que coincide con el previsto en los artículos 215-A del Código Penal Federal y 168 del Código Penal del Distrito Federal) tiene esa naturaleza, en tanto que se consuma momento a momento durante todo el tiempo en que la víctima se encuentra desaparecida, ha de concluirse que el plazo para que opere su prescripción de acuerdo con lo establecido en los numerales primeramente citados, empieza a correr hasta que la conducta ilícita deja de consumarse, esto es, cuando el sujeto pasivo aparece (vivo o muerto) o se establece su destino”. En DESAPARICIÓn FORZADA DE PERSONAS. El PLAZO PARA QUE OPERE SU PRESCRIPCIÓN INICIA HASTA QUE APARECE LA VÍCTIMA O SE ESTABLECE SU DESTinO. Pleno de la Suprema Corte de Justicia, Semanario Judicial de la Federación y su Gaceta, Novena Época, t. XX, septiembre de 2004, p. 1121. 
penal nacional que lograron empatar los criterios de derecho internacional de derechos humanos en la materia. ${ }^{97}$

\section{El CASO Rosendo RADiLla ANTE LA CORTE INTERAMERICANA DE DeReChos Humanos}

En el contexto de los procesos políticos, legislativos y judiciales antes mencionados, el 15 de noviembre de 2001 se interpuso una petición ante la Comisión Interamericana de Derechos Humanos denunciando la desaparición forzada de Rosendo Radilla Pacheco en 1974 en el marco de la llamada "guerra sucia".

En el momento en que los familiares iniciaron los procedimientos ante la Comisión Interamericana de Derechos Humanos aun era incierto el desarrollo de los procesos de incorporación del derecho internacional de los derechos humanos en relación con el crimen de desaparición forzada de personas en México. De hecho, el litigio del caso Radilla se desarrolló de forma paralela a los procesos nacionales de incorporación y los puntos importantes del caso se enfocan, precisamente, en las deficiencias de dichos procesos.

Además de los procesos ya descritos, es importante señalar que en 2001 la Comisión Nacional de los Derechos Humanos emitió la Recomendación 26/2001 relativa a "Las desapariciones forzadas de personas durante la década de los años setenta y principios de los ochenta del siglo pasado", la cual a su vez dio origen a la Fiscalía Especial para Movimientos Sociales y Políticos del Pasado (Femospp) que analizó más de 500 expedientes y diversas denuncias entre ellas la del Caso Radilla. ${ }^{98}$

97 En general revísense los razonamientos en la sentencia de la Controversia: Suprema Corte de Justicia de la Nación. Controversia CONSTituCiOnal 33/2002. Jefe DE GObierNo Del Distrito Federal. Ponente: ministro Juan Díaz Romero. Semanario Judicial de la Federación y su Gaceta, Novena Época, t. XX, agosto de 2004, p. 959.

98 Ferrer Mac-Gregor, Eduardo y Silva García, Fernando, Jurisdicción militar y derechos humanos. El caso Radilla ante la Corte Interamericana de Derechos Humanos, México, Porrúa-UNAM, 2011 , p. 3. 
Si bien es cuestionable el que la Fiscalía Especial no haya cumplido su propósito para el que fue creada, que era lograr las convicciones de los autores intelectuales y materiales de los delitos investigados, a partir de su trabajo fue posible la elaboración de un Informe Histórico a la Sociedad Mexicana, en el que se detallaron los patrones de violación a derechos humanos de la época y se documentaron cientos de casos, entre ellos, la desaparición forzada de Rosendo Radilla. ${ }^{99}$

El caso de Rosendo Radilla eventualmente fue remitido por la Comisión Interamericana a la Corte Interamericana de Derechos Humanos. El alto tribunal dictó sentencia sobre Excepciones Preliminares, Fondo, Reparaciones y Costas el 23 de noviembre de 2009. ${ }^{100}$

\section{La desaparición forzada de Rosendo Radilla Pacheco}

\section{A. ¿Quién fue Rosendo Radilla Pacheco?}

Según los hechos probados en el caso ante la Corte Interamericana de Derechos Humanos, Rosendo Radilla Pacheco nació el 20 de marzo de 1914 en Las Clavellinas, estado de Guerrero, México. ${ }^{101}$ Rosendo Radilla Pacheco estuvo involucrado en diversas actividades en la vida política y en obras sociales en Atoyac de Álvarez, Guerrero, en particular, en la organización de caficultores y campesinos de la zona. ${ }^{102}$ El

99 Cfr. Fiscalía Especial para Movimientos Sociales y Políticos del Pasado,Informe Histórico a la Sociedad Mexicana, 2006, 742 pp. El informe se puede consultar de forma electrónica en el Portal del proyecto independiente, no gubernamental "The National Security Archive" en la siguiente dirección: http: / /www.gwu.edu/ nsarchiv/NSAEBB/NSAEBB209/index.htm\#informe.

100 Corte IDH. Caso Radilla Pacheco vs. México, Excepciones Preliminares, Fondo, Reparaciones y Costas, Serie C, núm. 209, sentencia del 23 de noviembre de 2009.

101 Ibidem, párr. 120.

102 El señor Rosendo Radilla Pacheco formó parte de la Unidad Agraria de la Sierra Cafetalera de Atoyac de Álvarez. Entre el 1o. de junio de 1955 y el 31 de agosto de 1956 fue presidente del Consejo Municipal de Atoyac de Álvarez. En septiembre de 1956 desarrolló gestiones como presidente municipal. De 1956 a 1960 fue secretario general del Comité Regional Campesino. En 1961 fue presidente de la sociedad de padres de familia del Patronato Pro Escuela Federal Modesto Alarcón. En 1965 participó en la fundación de la Liga Agraria del Sur Emiliano Zapata. Entre sus distintas ocupaciones se encontraba también el cultivo del café y coco, así como la compra y venta de ganado Cfr. Ibidem, párr. 121. 
señor Rosendo Radilla Pacheco también componía "corridos", en los que relataba diversos hechos sucedidos en Atoyac de Álvarez y las luchas campesinas y sociales de la época. ${ }^{103}$

\section{B. La desaparición forzada de Rosendo Radilla}

Según determinó la Corte IDH, el 25 de agosto de 1974 Rosendo Radilla Pacheco, de 60 años de edad, y su hijo Rosendo Radilla Martínez, de 11 años de edad, viajaban en un autobús desde Atoyac de Álvarez a Chilpancingo, Guerrero. El autobús fue detenido en un retén en donde militares hicieron descender a todos los pasajeros para inspeccionarlos. Posteriormente, los pasajeros abordaron nuevamente el autobús para continuar el viaje. ${ }^{104} \mathrm{El}$ autobús fue detenido en un segundo retén. Los agentes militares solicitaron a los pasajeros descender del autobús para revisar su interior. Seguidamente, se indicó a los pasajeros que abordaran el autobús, excepto al señor Rosendo Radilla Pacheco, quien quedó detenido porque “componía corridos”. El señor Radilla Pacheco indicó que eso no constituía ningún delito; sin embargo, un militar le respondió "mientras, ya te chingaste". ${ }^{105}$

El señor Rosendo Radilla Pacheco solicitó a los militares que dejaran ir a su hijo, Rosendo Radilla Martínez, por ser un menor, a lo cual accedieron. Asimismo, pidió a su hijo que avisara a la familia que había sido detenido por el Ejército mexicano. El señor Radilla Pacheco quedó a disposición de la Zona Militar de Guerrero. ${ }^{106}$

Posteriormente a su detención, el señor Rosendo Radilla Pacheco fue visto en el Cuartel Militar de Atoyac de Álvarez con signos de maltrato físico. ${ }^{107}$ Sin embargo, nunca fue puesto en libertad y en la actualidad se desconoce su paradero. ${ }^{108}$

Los familiares del señor Rosendo Radilla Pacheco, al conocer de su detención, realizaron diversas gestiones para localizarlo, especialmente

103 Ibídem, párr. 122.

104 Ibídem, párr. 124.

105 Ibídem, párr. 125.

106 Ibídem, párr. 126.

107 Ibídem, párr. 128.

108 Ibídem, párr. 154. 
a través del contacto de familiares o conocidos que trabajaban para el Estado. No obstante, los familiares afirmaron en el proceso ante la Corte IDH que, por las condiciones de represión existentes en la época, reconocidas por el Estado, se inhibieron de presentar denuncias formales sobre los hechos. ${ }^{109} \mathrm{Al}$ respecto, la Corte consideró de suma importancia la declaración de la señora Tita Radilla, quien al formular denuncia el 14 de mayo de 1999, indicó que "[l]a persona que se presentaba a reclamar la aparición de algún pariente en ese momento era detenida, teníamos que desaparecer de la región para no ser detenidos”. ${ }^{110}$

C. El contexto de represión en la época y región donde desapareció Rosendo Radilla

Para la Corte IDH fue especialmente relevante el hecho de que se haya documentado que en la época en que fue detenido y desaparecido el señor Rosendo Radilla Pacheco, en diversas partes del territorio mexicano tuvieron lugar numerosas desapariciones forzadas de personas. El Tribunal consideró de gran relevancia lo señalado por la Comisión Nacional de los Derechos Humanos, en el marco del Programa Especial sobre Presuntos Desaparecidos, en ese sentido. ${ }^{111}$

A su vez, para la Corte IDH fue determinante el Informe rendido por la Femospp en el que se refirió a la existencia, en la época en que fue detenido Rosendo Radilla Pacheco, de un patrón de detenciones, tortura y desapariciones forzadas de personas militantes de la guerrilla o identificados como sus simpatizantes. ${ }^{12}$

Para la Corte, el Informe de la Fiscalía Especial documentó acciones militares desplegadas en el estado de Guerrero que revelan lo que pudieron ser los antecedentes de la detención del señor Radilla Pacheco. En tal informe la Corte IDH tomó en cuenta que se indicó que "[s]e calculaba que para 1971 el Ejército tenía concentrado[s] en Guerrero 24,000 soldados, una tercera parte de todos sus efectivos”, y que, para esa época, la Brigada Campesina de Ajusticiamiento del Partido Comu-

\footnotetext{
109 Ibídem, párr. 131.

110 Ibidem, párr. 131.

111 Ibidem, párr. 132.

112 Ibidem, párr. 136.
} 
nista de los Pobres, liderada por Lucio Cabañas "era la que tenía el control de una amplia zona” de la sierra, por lo que “[e]l Ejército hostig[ó] a las comunidades [y] det[uvo] a los pobladores acusándolos de abastecer a Lucio [Cabañas]". ${ }^{113} \mathrm{Al}$ respecto, destacó que luego del secuestro del entonces gobernador electo del estado de Guerrero, Rubén Figueroa, por parte de la Brigada Campesina, ocurrido el 6 de junio de 1974, semanas antes de la detención del señor Rosendo Radilla Pacheco, "[l]a respuesta del Ejército fue brutal en contra de las comunidades campesinas, a las que consideró como bases del movimiento guerrillero". Según el informe, el Ejército buscó "[l]a aniquilación de todo resabio de la guerrilla, arrasando a sangre y fuego, a todo partidario o sospechoso de simpatizar con la guerrilla, con el Partido de los Pobres, o con la izquierda...”. ${ }^{114}$

$\mathrm{Al}$ respecto, el Estado en su defensa trató de desvirtuar el informe de la Fiscalía Especial argumentando que "dicho documento no t[enía] un carácter oficial ni el gobierno le otorga[ba] una validación oficial”. Además, el Estado mexicano argumentó que "[s]olamente con los resultados de las averiguaciones previas que integran las indagatorias podría determinarse... la verdad histórica y no únicamente a partir del contexto que refleja el informe....". ${ }^{115}$

Sin embargo, la Corte IDH, siguiendo su jurisprudencia en el sentido de otorgar un valor probatorio especial a los informes de Comisiones de la Verdad o de Esclarecimiento Histórico como pruebas relevantes en la determinación de los hechos y de la responsabilidad internacional de los Estados determinó la válidez de dicho informe. Para la Corte IDH fue relevante, por una parte, que el Informe haya sido elaborado por personas que ostentaron en su momento la calidad de funcionarios públicos y que por otra, el Estado no haya desvirtuado la información particular ahí contenida ni las fuentes consultadas para su elaboración. ${ }^{116}$

Así la Corte IDH determinó, a partir del patrón de represión en la época, que el señor Rosendo Radilla Pacheco fue detenido por ser

113 Ibidem, párr. 137.

114 Ibidem, párr. 137.

115 Ibidem, párr. 73.

116 Ibidem, párr. 75 y 76. 
considerado simpatizante de la guerrilla. ${ }^{117} \mathrm{~A}$ partir del acervo probatorio, la Corte IDH estableció que detenciones como éstas se realizaban sin orden expedida por autoridad competente y en la clandestinidad, teniendo como propósito sustraer al individuo de la protección de la ley, con el fin de quebrantar su personalidad y obtener confesiones o informaciones sobre la insurgencia. ${ }^{118}$

\section{La decisión de la Corte IDH en torno a la violación}

de los derechos humanos de Rosendo Radilla y sus familiares

En un litigio internacional ante el sistema interamericano de derechos humanos muchas cuestiones de gran relevancia para un país son decididas. En el presente artículo nos referiremos a aquellos criterios tomados por la Corte IDH en el caso Rosendo Radilla que tienen una fuerte conexión con lo ya comentado en apartados anteriores: el alcance de la declaración interpretativa y la validez de la reserva a la Convención Interamericana sobre Desaparición Forzada de Personas, la configuración de la desaparición de Rosendo Radilla como una violación pluriofensiva y continuada a sus derechos y por último, la incompatibilidad con la Convención Interamericana sobre Desaparición Forzada de Personas del tipo penal del delito de desaparición forzada a nivel federal.

A. La decisión de la Corte IDH respecto al alcance de la declaración interpretativa a la Convención Interamericana sobre Desaparición Forzada de Personas

En primer término, en el litigio del caso Radilla, a diferencia de otros casos de desaparición forzada de personas en el sistema interamericano, existían dos cuestiones legales que tenían que ser resueltas por la Corte con el fin de clarificar el ámbito de su competencia al resolver el fondo del caso. Para ello, fue necesario revisar el alcance tanto de la

117 Ibidem, párr. 151.

118 Idem. 
declaración interpretativa como el de la reserva realizada por México a la Convención Interamericana sobre Desaparición Forzada de Personas.

Respecto a la declaración y la reserva formuladas por México a dicha Convención se vertieron una gran cantidad de argumentos por parte de la representación del Estado para sostenerlas. Algunas de dichas objeciones se desprendían de cuestiones procesales, pero otras sí planteaban cuestiones verdaderamente de fondo. En este análisis nos enfocaremos solamente en las segundas. ${ }^{119}$

Respecto a la declaración interpretativa, el alegato más fuerte del Estado fue planteado a manera de excepción preliminar, en donde se arguyó que conforme a la declaración interpretativa formulada al ratificar la Convención Interamericana sobre Desaparición Forzada de Personas por México, la Corte IDH carecía de competencia ratione temporis para aplicar dicho instrumento internacional respecto a hechos que "no se hubieran ordenado, ejecutado o cometido con posterioridad a la entrada en vigor del referido tratado". ${ }^{120}$ Es decir, el Estado mexicano alegó que la Corte IDH no poseía competencia sobre el caso porque supuestamente la desaparición forzada de Rosendo Radilla se había ordenado, ejecutado y cometido en 1974, mucho antes de que la Convención Interamericana en la materia entrara en vigor, en 2002.

Recordando, la declaración interpretativa a la Convención Interamericana sobre Desaparición Forzada de Personas menciona específicamente que:

Con fundamento en el artículo 14 de la Constitución Política de los Estados Unidos Mexicanos... se entenderá que las disposiciones de dicha Convención se aplicarán a los hechos que constituyan desaparición forzada de personas, se ordenen, ejecuten o cometan con posterioridad a la entrada en vigor de la presente Convención.

119 Dentro de los múltiples alegatos del Estado con el fin de preservar el sentido tanto la declaración como la reserva se alegó inter alia que los representantes no habían objetado dicho contenido previamente en el litigio ante la Comisión y que la Corte IDH no tenía competencia para pronunciarse sobre este tema.

120 Corte IDH. Caso Radilla Pacheco vs. México, Excepciones Preliminares, Fondo, Reparaciones y Costas, Serie C, núm. 209, sentencia del 23 de noviembre de 2009, párr. 26. 
Sobre esta solicitud, la Corte IDH determinó que la interpretación correcta de los términos "ejecutan o cometan" de la declaración interpretativa realizada por México a la Convención Interamericana sobre Desaparición Forzada de Personas, no puede ser otra que una consecuente con la caracterización que el propio tratado realiza de la desaparición forzada y con el efecto útil de sus disposiciones, de manera que su aplicación incluya los actos de desaparición forzada de personas que continúen o permanezcan más allá de la fecha de entrada en vigor para México, es decir, el 9 de abril de 2002 (fecha de depósito ante la OEA), en tanto no se establezca el destino o paradero de la víctima. ${ }^{121}$

Para la Corte IDH el hecho de que Rosendo Radilla siga desaparecido actualiza el crimen de desaparición forzada incluso después del 9 de abril de 2002, de ahí que la eventual aplicación de la Convención Interamericana sobre Desaparición Forzada de Personas al presente caso se encontrara dentro de la competencia temporal de la Corte IDH. ${ }^{122} \mathrm{Si}$ recordamos, la misma discusión se dio en el trámite de la Controversia Constitucional 33/2002 con idénticos resultados.

\section{B. La decisión de la Corte IDH respecto a la reserva formulada} por México a la Convención Interamericana sobre Desaparición Forzada de Personas en relación con la actuación de la justicia militar en este tipo de casos

El caso de Rosendo Radilla, en su etapa procesal ante las autoridades nacionales fue conocido por el fuero militar. De ahí que una de las grandes controversias haya sido la relativa a si la reserva a la Convención Interamericana sobre Desaparición Forzada de Personas era en efecto válida.

Como ya se ha comentado, México formuló una reserva al artículo IX de dicha Convención la cual señala:

121 Ibidem, párr. 31.

122 Ibidem, párr. 32. 
El Gobierno de los Estados Unidos Mexicanos al ratificar la Convención Interamericana sobre Desaparición Forzada de Personas, adoptada en la Ciudad de Belem, Brasil el 9 de junio de 1994, formula reserva expresa al Artículo IX, toda vez que la Constitución Política reconoce el fuero de guerra, cuando el militar haya cometido algún ilícito encontrándose en servicio. El fuero de guerra no constituye jurisdicción especial en el sentido de la Convención, toda vez que conforme al artículo 14 de la Constitución mexicana nadie podrá ser privado de la vida, de la libertad o de sus propiedades, posesiones o derechos, sino mediante juicio seguido ante los tribunales previamente establecidos, en el que se cumplan las formalidades esenciales del procedimiento y conforme a las leyes expedidas con anterioridad al hecho.

En relación con la facultad de formular reservas, la Corte IDH consideró importante atender a lo dispuesto por el artículo XIX de la Convención Interamericana sobre Desaparición Forzada de Personas que dispone que "[l]os Estados podrán formular reservas a [esta] Convención en el momento de aprobarla, firmarla, ratificarla o adherirse a ella, siempre que no sean incompatibles con el objeto y propósito de la Convención y versen sobre una o más disposiciones específicas". ${ }^{123}$

En cuanto a su compatibilidad con el objeto y fin del tratado, la Corte advirtió que, a través de la reserva, México estableció que el fuero de guerra es competente para conocer de un caso de desaparición forzada si el delito es cometido por un militar en servicio. Esto implica, para el alto tribunal, referirse a un fuero que para ser aplicado requiere de una calificación personal, no material. Asimismo, al añadir una reserva al artículo IX de la Convención Interamericana sobre Desaparición Forzada de Personas, el Estado mexicano estableció una regla general sobre la competencia de la jurisdicción penal militar a diferencia de una de carácter excepcional que necesariamente requiere justificación en el caso concreto, propia de un régimen democrático. ${ }^{124}$

Una cuestión fundamental para el análisis de esta reserva era lo relativo al objeto y fines de la Convención Interamericana sobre Desaparición Forzada de Personas. Para la Corte, dentro de estos parámetros

123 Ibidem, párr. 301.

124 Ibidem, párr. 307. 
se encuentra el lograr la efectiva sanción de los autores del delito de desaparición forzada, teniendo acceso al juez natural, indisolublemente ligado al derecho al debido proceso y al de acceso a la justicia. Para la Corte IDH, los Estados parte en la Convención Interamericana sobre Desaparición Forzada de Personas se comprometen a respetar el derecho a un juez competente para conocer de la causa penal en torno al delito de desaparición forzada, que es el juez común, ya que el bien jurídico protegido trasciende los intereses militares. ${ }^{125}$

La Corte con ocasión de la Opinión Consultiva 3/83 relativo a las restricciones a la pena de muerte estableció que "una reserva que suspenda todo el derecho fundamental cuyo contenido es inderogable debe ser considerada como incompatible con el objeto y el propósito de la Convención y, consecuentemente, incompatible con la misma”. ${ }^{126}$

Para el tribunal, tal y como fue formulada la reserva al artículo IX de la Convención Interamericana sobre Desaparición Forzada de Personas implicó el desconocimiento del derecho humano al juez natural en la debida investigación y eventual sanción de los responsables de la comisión de desaparición forzada de personas. La necesidad de asegurar que este tipo de casos sean investigados ante las instancias competentes de conformidad con las obligaciones internacionales, trasciende los intereses de los Estados. ${ }^{127}$

Así, la Corte IDH determinó que la reserva formulada por México no satisfacía el primer requisito establecido en el artículo XIX de la Convención Interamericana sobre Desaparición Forzada de Personas, por lo que, en consecuencia, debía ser considerada inválida. ${ }^{128}$ Es importante señalar que a la declaración de invalidez de la reserva debe otorgársele efectos generales y considerarla inválida in toto, tal y como lo ha hecho la Corte IDH al evaluar otro tipo de disposiciones que han resultado invalidas a la luz de la Convención Americana sobre Derechos Humanos. ${ }^{129}$

125 Ibidem, párr. 309.

126 Cfr. Restricciones a la Pena de Muerte (artículos 4.2 y 4.4 Convención Americana sobre Derechos Humanos). Opinión Consultiva OC-3/83, párr. 60.

127 Corte IDH, Caso Radilla Pacheco vs. México, Excepciones Preliminares, Fondo, Reparaciones y Costas, Serie C, núm. 209, sentencia del 23 de noviembre de 2009, párr. 311.

128 Ibidem, párr. 312.

129 Cfr. Corte IDH, Caso Barrios Altos vs. Perú, Interpretación de la Sentencia de Fondo, Serie C, núm. 83, sentencia del 3 de septiembre de 2001. 
Es de destacar que existía ya al menos un precedente internacional respecto a este tipo de reservas, como sucedió en el caso Bellilios en el Sistema Europeo de Derechos Humanos. ${ }^{130}$ En este mismo orden de ideas, Sergio García Ramírez, ex presidente de la Corte IDH, ha señalado que dicha declaratoria de invalidez por parte de la Corte Interamericana era "previsible". Esto, en opinión del jurista mexicano, debería invitarnos a reflexionar sobre el contenido de otras declaraciones interpretativas y otras reservas realizadas por México a tratados de derechos humanos. ${ }^{131}$ A partir de lo afirmado por García Ramírez y de lo constatado en el caso Radilla, tal vez deberíamos empezar a ver las reservas y declaraciones interpretativas realizadas por México a tratados y convenciones de derechos humanos dentro de una suerte de "categoría sospechosa" (valga la mutación del término) en el plano del derecho internacional de los derechos humanos, prima facie contrarias al objeto y fin de un tratado de derechos humanos, las cuales deberían ser sometidas a algún tipo de escrutinio por parte de los tribunales nacionales, ya que no todos los tratados de derechos humanos tienen la ventaja de los instrumentos del sistema interamericano de derechos humanos de contar con una institución jurisdiccional que pueda controlar y en su caso corregir este tipo de situaciones. Un ejemplo de ello es la declaración interpretativa a la Convención sobre la Imprescriptibilidad de los Crímenes de Guerra y de los Crímenes de Lesa Humanidad mencionada líneas arriba, entre muchas otras.

\section{La desaparición forzada del señor Rosendo Radilla Pacheco} como una violación pluriofensiva y continuada a sus derechos humanos

La Corte IDH en el caso Rosendo Radilla, reiteró que la desaparición forzada de personas constituye una violación múltiple de varios derechos protegidos por la Convención Americana que coloca a la víctima en un estado de completa indefensión, acarreando otras vulneraciones

130 ECHR, Case Bellilios v. Switzerland, 10 Eur. Ct. H.R. 466, 492 P 78 (1988).

131 Véase García Ramírez, Sergio, "Prólogo" en La sentencia de la Corte IDH. Caso Radilla PachecoVs. Estados Unidos Mexicanos. México, CMDPDH, 2010, p. 9, y García Ramírez, Sergio, La Corte Penal Internacional, México, INACIPE, 2004, p. 165. 
conexas, siendo particularmente grave cuando forma parte de un patrón sistemático o práctica aplicada o tolerada por el Estado. ${ }^{132}$ Así, la caracterización pluriofensiva y continuada o permanente de la desaparición forzada se desprende no sólo de la propia definición del artículo III de la Convención Interamericana sobre Desaparición Forzada de Personas, sino también de la configuración misma de esta conducta en la jurisprudencia de la Corte IDH. En este aspecto, para la Corte IDH resultó relevante considerar que la misma Suprema Corte de Justicia de la Nación de México, coincidió con esta caracterización en la Controversia Constitucional 33/2002. ${ }^{133}$

A partir de los hechos probados del caso anteriormente comentados, la Corte IDH estimó suficientemente acreditado que el señor Rosendo Radilla Pacheco fue detenido por militares del Ejército en un retén el 25 de agosto de 1974, y posteriormente trasladado al Cuartel Militar de Atoyac de Álvarez. Ahí habría permanecido detenido de forma clandestina por varias semanas, donde fue visto por última vez, con los ojos vendados y signos de maltrato físico. Hasta la fecha, los familiares del señor Radilla Pacheco desconocen su paradero, a pesar de las gestiones realizadas. ${ }^{134}$

Para la Corte IDH, la desaparición del señor Radilla Pacheco no sólo es, a todas luces, contraria al derecho a la libertad personal, sino, además, se enmarcó en un patrón de detenciones y desapariciones forzadas masivas, lo cual permitió concluir que aquélla lo colocó en una grave situación de riesgo de sufrir daños irreparables a su integridad personal y a su vida. ${ }^{135}$ Adicionalmente, la desaparición forzada para el alto tribunal interamericano es violatoria del derecho a la integridad personal, según determinó en el caso Velásquez Rodríguez: "[e]l solo hecho del aislamiento prolongado y de la incomunicación coactiva, representa un

132 Corte IDH, Caso Radilla Pacheco vs. México, Excepciones Preliminares, Fondo, Reparaciones y Costas, Serie C, núm. 209, sentencia del 23 de noviembre de 2009, párr. 139.

133 Ibidem, párr. 140. Véase el contenido de la nota al pie 127 en la parte final del párrafo.

134 Ibidem, párr. 150.

135 Ibidem, párr. 152. 
tratamiento cruel e inhumano... en contradicción con los párrafos 1 y 2 del artículo 5 de la Convención”. ${ }^{136}$

De esta forma, la Corte IDH concluyó que el Estado era responsable por la violación de los artículos 7.1 (libertad personal); 5.1 y 5.2 (integridad personal); 3 (derecho al reconocimiento de la personalidad jurídica) y 4.1 (derecho a la vida), de la Convención Americana sobre Derechos Humanos, en perjuicio del señor Rosendo Radilla Pacheco, en razón del incumplimiento del deber de garantía y de respeto de dichos derechos, establecido en el artículo 1.1 del mismo instrumento internacional, todos ellos en relación con los artículos I y XI de la Convención Interamericana sobre Desaparición Forzada de Personas. ${ }^{137}$

Adicionalmente, siguiendo su jurisprudencia constante, la Corte IDH encontró que a partir de la desaparición del señor Rosendo Radilla, la situación de angustia, incertidumbre e impunidad generaron en sus familiares afectaciones a su integridad personal. ${ }^{138}$

Igualmente, la Corte IDH consideró que la investigación de la detención y posterior desaparición forzada del señor Rosendo Radilla Pacheco no había sido diligente, ni había sido asumida en su totalidad como un deber propio del Estado ni había estado dirigida eficazmente tanto a la identificación, proceso y eventual sanción de todos los responsables como a la determinación del paradero del señor Radilla Pacheco. Asimismo, el tribunal estimó que al extender la competencia del fuero castrense a delitos que no tienen estricta conexión con la disciplina militar o con bienes jurídicos propios del ámbito castrense, en virtud del artículo 57 del Código de Justicia Militar, ${ }^{139}$ el Estado vulneró el derecho al juez natural de los familiares del señor Rosendo Radilla Pacheco, quie-

136 Ibidem, párr. 153. Corte IDH. Caso Velásquez Rodríguez vs. Honduras, Fondo, sentencia del 29 de julio de 1988, Serie C, núm. 4, párrs. 156 y 187.

137 Ibidem, párr. 154 y 159.

138 Ibidem, párr. 172.

139 El Código de Justicia Militar dispone en su artículo 57:

Son delitos contra la disciplina militar:

I. - Los especificados en el Libro Segundo de este Código;

II.- los del orden común o federal, cuando en su comisión haya concurrido cualquiera de las circunstancias que en seguida se expresan:

a).- Que fueren cometidos por militares en los momentos de estar en servicio o con motivo de actos del mismo; 
nes tampoco dispusieron de un recurso que les permitiera impugnar el juzgamiento de la detención y posterior desaparición forzada de la víctima por la jurisdicción militar. Todo ello en detrimento del derecho a conocer la verdad de aquéllos. ${ }^{140}$ Más aun, la Corte IDH determinó que la jurisdicción penal militar no es el fuero competente para investigar y, en su caso juzgar y sancionar a los autores de violaciones de derechos humanos, sino que el procesamiento de los responsables corresponde siempre a la justicia ordinaria. ${ }^{141}$

De esta forma, la Corte IDH determinó que el Estado mexicano había violado los derechos reconocidos en los artículos 8.1 y 25.1 de la Convención Americana, en relación con los artículos 1.1 y 2 de la misma, y I incisos $a$ y $b$, y IX de la Convención Interamericana sobre Desaparición Forzada de Personas, así como con los artículos I d y XIX del mismo instrumento internacional. ${ }^{142}$

D. La incompatibilidad de la tipificación del delito de desaparición forzada de personas a nivel federal

b).- que fueren cometidos por militares en un buque de guerra o en edificio o punto militar u ocupado militarmente, siempre que, como consecuencia, se produzca tumulto o desorden en la tropa que se encuentre en el sitio donde el delito se haya cometido o se interrumpa o perjudique el servicio militar;

c).- que fueren cometidos por militares en territorio declarado en estado de sitio o en lugar sujeto a la ley marcial conforme a las reglas del derecho de la guerra;

d).- que fueren cometidos por militares frente a tropa formada o ante la bandera;

e).- que el delito fuere cometido por militares en conexión con otro de aquellos a que se refiere la fracción I.

Cuando en los casos de la fracción II, concurran militares y civiles, los primeros serán juzgados por la justicia militar.

Los delitos del orden común que exijan querella, necesaria para su averiguación y castigo, no serán de la competencia de los tribunales militares, sino en los casos previstos en los incisos (c) y (e) de la fracción II.

140 Corte IDH, Caso Radilla Pacheco vs. México, Excepciones Preliminares, Fondo, Reparaciones y Costas, sentencia del 23 de noviembre de 2009, Serie C, núm. 209, párr. 313.

141 Ibidem, párr. 273.

142 Ibidem, párr. 314. 
Sin embargo, en la Corte IDH faltaba un tema más por resolver: ¿se encontraba correctamente tipificado el delito de desaparición forzada de personas en la legislación federal en México?

Como antecedente, hay que mencionar que los Estados partes en la Convención Americana tienen el deber general de adecuar su derecho interno a las disposiciones de dicho tratado para garantizar los derechos que éste consagra. En el caso de la desaparición forzada de personas, la Corte IDH ha sido clara en que esta obligación se corresponde con el artículo I d de la Convención Interamericana sobre Desaparición Forzada de Personas, el cual establece que los Estados parte en la misma se comprometen a tomar las medidas de carácter legislativo, administrativo, judicial o de cualquier otra índole, necesarias para cumplir con los compromisos por ellos asumidos. ${ }^{143}$

La obligación de adoptar medidas de derecho interno implica que los Estados deben tipificar el delito de desaparición forzada, en este sentido se expresa el artículo III de la Convención Interamericana sobre Desaparición Forzada de Personas. La Corte IDH, en el caso Gómez Palomino estableció que la descripción del delito de desaparición forzada de personas debe hacerse tomando en consideración el artículo II de la citada Convención, el cual establece un estándar mínimo acerca de su correcta tipificación en el ordenamiento jurídico interno. ${ }^{144} \mathrm{El}$ artículo en cuestión dispone que:

Para los efectos de la presente Convención, se considera desaparición forzada la privación de la libertad a una o más personas, cualquiera que fuere su forma, cometida por agentes del Estado o por personas o grupos de personas que actúen con la autorización, el apoyo o la aquiescencia del Estado, seguida de la falta de información o de la negativa a reconocer dicha privación de libertad o de informar sobre el paradero de la persona, con lo cual se impide el ejercicio de los recursos legales y de las garantías procesales pertinentes.

143 Ibidem, párr. 317.

144 Cfr. Corte IDH, Caso Gómez Palomino vs. Perú, Fondo, Reparaciones y Costas, sentencia del 22 de noviembre de 2005, Serie C, núm. 136. 
La Corte advirtió que el delito de desaparición forzada se encuentra sancionado en el artículo 215-A del Código Penal Federal de México desde 2001, en los siguientes términos:

Comete el delito de desaparición forzada de personas, el servidor público que, independientemente de que haya participado en la detención legal o ilegal de una o varias personas, propicie o mantenga dolosamente su ocultamiento bajo cualquier forma de detención.

En primer lugar, la Corte IDH observó que dicha disposición restringe la autoría del delito de desaparición forzada de personas a "servidores públicos”. En tal sentido, en cuanto al sujeto activo del delito, la Corte había establecido previamente en el caso Gómez Palomino vs. Perú que, en términos del artículo II de la Convención Interamericana sobre Desaparición Forzada de Personas, la disposición que describe el tipo penal debe asegurar la sanción de todos los "autores, cómplices y encubridores del delito de desaparición forzada de personas", sean agentes del Estado o "personas o grupos de personas que actúen con la autorización, el apoyo o la aquiescencia del Estado”. ${ }^{145}$

Así, para la Corte IDH, el tipo penal de desaparición forzada de personas del Código Penal Federal presenta un obstáculo para asegurar la sanción de "todos los autores, cómplices y encubridores" provenientes de "cualesquiera de los poderes u órganos del Estado". Para satisfacer los elementos mínimos de la correcta tipificación del delito, el carácter de "agente del Estado" debe ser establecido de la forma más amplia posible. ${ }^{146}$ Asimismo, el Tribunal advirtió que el artículo 215-A del citado Código Penal Federal no se refiere a "personas o grupos de personas que actúen con la autorización, el apoyo o la aquiescencia del Estado”. ${ }^{147}$

La Corte IDH señaló que la desaparición forzada de personas se caracteriza por la negativa de reconocer la privación de libertad o dar información sobre la suerte o el paradero de las personas y por no de-

145 Ibidem, párr. 101. Sobre este tema consúltese con especial atención el voto del juez Sergio García Ramírez.

146 Corte IDH. Caso Radilla Pacheco Vs. México. Excepciones Preliminares, Fondo, Reparaciones y Costas. Sentencia de 23 de Noviembre de 2009. Serie C No. 209, párr. 321.

147 Ibidem, párr. 322. 
jar huellas o evidencias. Dicho elemento, para ese alto tribunal, debía estar presente en la tipificación del delito porque permite distinguir una desaparición forzada de otros ilícitos con los que usualmente se la relaciona, como el plagio o secuestro y el homicidio, con el propósito de que puedan ser aplicados los criterios probatorios adecuados e impuestas las penas que consideren la extrema gravedad de este delito a todos aquellos implicados en el mismo. En el caso de la legislación penal federal, la Corte observó que el artículo 215-A del Código Penal Federal no incluía dicho elemento, por lo cual resultaba incompleta la tipificación del delito. ${ }^{148}$

La Corte así determinó que el tipo penal de desaparición forzada a nivel federal no posee una adecuación que haga plenamente efectiva la normativa internacional vigente sobre la materia. En tal sentido, la Corte Interamericana consideró que México no cumplió plenamente las obligaciones que le impone el artículo 2o. de la Convención Americana, en relación con los artículos I y III de la Convención Interamericana sobre Desaparición Forzada de Personas, para garantizar debidamente la investigación y eventual sanción de los hechos constitutivos de desaparición forzada en el caso Radilla. ${ }^{149}$

\section{Las medidas de reparación ordenadas por la Corte Interamericana}

A partir de los hechos probados del caso y de las violaciones declaradas, la Corte Interamericana otorgó un amplio espectro de medidas de reparación ${ }^{150}$ dentro de las cuales se dictaron varias medidas de alcance general relacionadas con los puntos de derecho ya discutidos, entre las que encontramos:

a) La obligación de adoptar, en un plazo razonable, las reformas legislativas pertinentes para compatibilizar el artículo 57 del Código de

148 Ibidem, párr. 323.

149 Ibidem, párr. 324.

150 Respecto a la naturaleza de las medidas de reparación en el Sistema Interamericano de Derechos Humanos consúltese: Shelton, Dinah, Remedies in International Human Rights Law, 2a. ed., Nueva York, Oxford University Press, 2006, pp. 255 y ss. 
Justicia Militar con los estándares internacionales en la materia y de la Convención Americana sobre Derechos Humanos. ${ }^{151}$

Al respecto, cabe destacar que para la Corte IDH, el artículo 13 constitucional no es la norma que da competencia a la jurisdicción militar en casos de violaciones a derechos humanos sino es la interpretación que hace de este precepto constitucional el artículo 57 del Código de Justicia Militar, de ahí que se ordene su adecuación.

b) La obligación de adoptar, en un plazo razonable, las reformas legislativas pertinentes para compatibilizar el artículo 215 A del Código Penal Federal con los estándares internacionales en la materia y de la Convención Interamericana sobre Desaparición Forzada de Personas. ${ }^{152}$

Esta medida de reparación se tomó en virtud de las razones ya expuestas con anterioridad, y la Corte IDH también ordenó:

c) La obligación de implementar, en un plazo razonable y con la respectiva disposición presupuestaria, programas o cursos permanentes relativos al análisis de la jurisprudencia del Sistema Interamericano de Protección de los Derechos Humanos en relación con los límites de la jurisdicción penal militar, así como un programa de formación sobre la debida investigación y juzgamiento de hechos constitutivos de desaparición forzada de personas. ${ }^{153}$

Respecto a esta última medida de reparación, la Corte ordenó específicamente implementar diversos programas de capacitación para funcionarios públicos, incluyendo a jueces. ${ }^{154}$ Además, la Corte especificó que dentro de dichos programas se deberá hacer especial mención a la

151 Corte IDH, Caso Radilla Pacheco vs. México, Excepciones Preliminares, Fondo, Reparaciones y Costas, sentencia del 23 de noviembre de 2009, Serie C, núm. 209, punto resolutivo 10.

152 Ibidem, Punto Resolutivo 11.

153 Ibidem, Punto Resolutivo 12.

154 Ibidem, párr. 347. 
sentencia del Caso Radilla y a los instrumentos internacionales de derechos humanos de los que México es parte. ${ }^{155}$

Cabe señalar que son en particular estas tres medidas de reparación las que están en la actualidad impulsando el debate en torno al caso, como lo analizaremos a continuación.

\author{
V. LAS IMPLICACIONES DE LA SENTENCIA EN EL CASO ROSENDO \\ RADILLA EN EL PROCESO DE INCORPORACIÓN DE LOS ESTÁNDARES \\ INTERNACIONALES EN MATERIA DE DESAPARICIÓN FORZADA \\ DE PERSONAS EN MÉXICO
}

La sentencia del caso Radilla, lejos de ser un colofón o final de esta historia se ha convertido en una piedra de toque que ha revitalizado el debate en torno a los estándares nacionales en materia de desaparición forzada de personas en México, y más aún, en conjunto con otros casos similares decididos por la Corte Interamericana de Derechos Humanos, se han vuelto en factores transformadores de nuestro sistema jurídico en materia de derechos humanos. Sin embargo, estos procesos ¿realmente son suficientes para cumplir con los estándares establecidos? A continuación nos referiremos a ellos brevemente.

1. Casos en contra del Estado mexicano decididos con posterioridad por la Corte IDH: los casos de Inés Fernández, Valentina Rosendo, y Cabrera García y Montiel Flores 
El caso Rosendo Radilla no es el único caso en el que se ha discutido la pertinencia del fuero militar en México. Con posterioridad a este caso la Corte decidió los casos de Inés Fernández ${ }^{156}$ y Valentina Rosendo, ${ }^{157}$ quienes fueron objeto de violencia sexual constitutiva del delito de tortura por parte de elementos del ejército en sus comunidades y el caso Cabrera García y Montiel Flores, mejor conocido como el caso de "los campesinos ecologistas", ${ }^{158}$ quienes fueron detenidos por el ejército y sometidos a tratos crueles, inhumanos y degradantes. El Estado en ningún momento investigó las denuncias interpuestas por hechos de tortura.

En todos estos casos se refrendó el razonamiento de la Corte Interamericana de Derechos Humanos respecto al amplio uso que se le da al fuero militar en México y recomendó, igualmente, amplias medidas de reparación que involucran la actuación de todos los poderes de la Unión. Asimismo, se encuentra el paradigmático caso Campo Algodonero que trata sobre crímenes en razón de género en Ciudad Juárez que también prevé medidas de reparación de amplio alcance ante la gravedad de los hechos del caso. ${ }^{159}$

Adicionalmente, en estos casos se exploró con detenimiento la doctrina del "control de convencionalidad", la cual, permitiría la aplicación de la Convención Americana sobre Derechos Humanos, así como de otros tratados del sistema interamericano de derechos humanos y su interpretación por parte de la Corte IDH por parte de los jueces nacionales de todos los niveles. En especial, el voto concurrente del juez ad hoc Ferrer Mac-Gregor en el Caso Cabrera García y Montiel Flores marcará, probablemente, el rumbo del debate de los próximos años en esta temática. ${ }^{160}$

156 Corte IDH, Caso Fernández Ortega y otros vs. México, Excepción Preliminar, Fondo, Reparaciones y Costas, sentencia del 30 de agosto de 2010, Serie C, núm. 215.

157 Corte IDH, Caso Rosendo Cantú y otra vs. México, Excepción Preliminar, Fondo, Reparaciones y Costas, sentencia del 31 de agosto de 2010, Serie C, núm. 216.

158 Corte IDH, Caso Cabrera García y Montiel Flores vs. México, Excepción Preliminar, Fondo, Reparaciones y Costas, sentencia del 26 de noviembre de 2010, Serie C, núm. 220.

159 Corte IDH, Caso González y otras (“Campo Algodonero") vs. México, Excepción Preliminar, Fondo, Reparaciones y Costas, sentencia del 16 de noviembre de 2009, Serie C, núm. 205.

160 Corte IDH, Voto razonado del Juez Eduardo Ferrer Mac-Gregor Poisot en el Caso Cabrera García y Montiel FloresVs. México, Excepción Preliminar, Fondo, Reparaciones y Costas, sentencia del 26 de noviembre de 2010, Serie C, núm. 220. 


\section{La Visita del Grupo de Trabajo sobre Desapariciones Forzosas}

o Involuntarias de Naciones Unidas

El Grupo de Trabajo de las Naciones Unidas sobre las Desapariciones Forzadas o Involuntarias visitó México del 18 al 31 de marzo de 2011. ${ }^{161}$ El objetivo de la visita fue conocer los esfuerzos del Estado mexicano en el tratamiento de las desapariciones forzadas. En especial, el Grupo examinó el estado de las investigaciones sobre casos tanto del pasado como recientes, las medidas adoptadas para prevenir y erradicar las desapariciones forzadas y combatir la impunidad, así como otros aspectos, incluidos temas relativos a la verdad, la justicia y la reparación para las víctimas de desapariciones forzadas. ${ }^{162}$

El Grupo de Trabajo encontró que las desapariciones perpetradas en el pasado continúan siendo una de las grandes tareas pendientes en el presente, toda vez que se trata de un delito de carácter continuado. ${ }^{163}$ Además, el Grupo encontró que la desaparición forzada de personas en México se enfoca en la actualidad en ciertos grupos vulnerables. Así, los casos recientes de desapariciones forzadas indican que entre las víctimas de este crimen se encuentran: menores, mujeres, migrantes, defensores de los derechos humanos, periodistas, así como activistas sociales y sindicales. ${ }^{164}$

El Grupo observó que no existe una política pública integral que se ocupe de los diferentes aspectos de prevención, investigación, sanción y reparación de las víctimas de desapariciones forzadas. Este panorama pareciera demostrar que no existe una coordinación vertical y hori-

161 La misión estuvo integrada por tres miembros del Grupo de Trabajo: la Sra. Jasminka Dzumhur (Bosnia y Herzegovina), el Sr. Ariel Dulitzky (Argentina) y el Sr. Osman El Hajjé (Líbano).

162 Cfr. Oficina del Alto Comisionado de los Derechos Humanos en México. Comunicado de Prensa, El Grupo de Trabajo sobre las desapariciones forzadas o involuntarias concluye su visita a México, Ginebra, 31 de marzo de 2011. El comunicado se encuentra disponible en: http:// www.hchr.org.mx/files/comunicados /2011/mayo/Desapariciones_finalOK.pdf.

163 Idem.

164 Idem. 
zontal entre las autoridades federales, locales y municipales, así como tampoco entre las autoridades del mismo nivel de gobierno. ${ }^{165}$

De esta forma, el Grupo de Trabajo llegó a la conclusión de que:

Las víctimas de desaparición forzada no confían en el sistema de justicia, ni en los Ministerios Públicos, la policía y las fuerzas armadas. La impunidad es un patrón crónico y presente en los casos de desapariciones forzadas y no se han realizado los esfuerzos suficientes para determinar la suerte o el paradero de las personas desaparecidas, para sancionar a los responsables, ni tampoco para brindar reparaciones. ${ }^{166}$

Finalmente, se emitieron una serie de recomendaciones preliminares que coinciden y van mucho más allá de lo dispuesto por la Corte IDH en el caso Radilla. En marzo de 2012, el Grupo presentará un informe final ante el Consejo de Derechos Humanos respecto a esta visita.

\section{La reforma constitucional en materia de derechos humanos de junio de 2011}

Paralelamente a los procesos descritos, desde un poco más de 10 años se lleva discutiendo en México cuál debe ser el lugar que debe ocupar el derecho internacional de los derechos humanos en nuestro orden normativo. Si bien, existieron varios esfuerzos por parte de la Suprema Corte de Justicia de la Nación para llegar a una conclusión por medio de la interpretación del artículo 133 constitucional. ${ }^{167}$ La respuesta al

165 Idem.

166 Idem.

167 Cfr. Suprema Corte de Justicia de la Nación. Novena Época. instancia: Pleno. Fuente: Semanario Judicial de la Federación y su Gaceta. Tomo X, noviembre de 1999. Tesis: P LXXVII/1999, bajo el rubro: "TRATADOS INTERNACIONALES. SE UBICAN JERÁRQUICAMENTE POR ENCIMA DE LAS LEYES FEDERALES Y EN UN SEGUNDO PLANO RESPECTO DE LA CONSTITUCIÓN FEDERAL"; Suprema Corte de Justicia de la Nación Juicio de Amparo en Revisión 120/2002, "Mac Cain México, S. A. de C.V., Tesis PVII/2007, t. XXV, de 20 de mayo de 2007, publicada en el Semanario Judicial de la Federación y su Gaceta, "LEYES GENERALES. INTERPRETACIÓN DEL ARTíCUlo 133 CONSTITUCIONAL", y Suprema Corte de Justicia de la Nación Juicio de Amparo en Revisión 120/2002, "Mac Cain México, S. A. de C.V., Tesis P. IX/2007, Tomo XXV, de 
parecer se dará a través del párrafo segundo del artículo 1o. de la Constitución, que dispone que:

Las normas relativas a los derechos humanos se interpretarán de conformidad con esta Constitución y con los tratados internacionales de la materia favoreciendo en todo tiempo a las personas la protección más amplia.

Esta nueva redacción del texto constitucional surgió de un proceso plural en donde participaron organizaciones de la sociedad civil y académicos de diversas instituciones. ${ }^{168}$ Esta disposición publicada en junio de 2011 ofrece la posibilidad de que a través de la cláusula de interpretación conforme y el principio pro persona se constituya un verdadero "bloque de constitucionalidad" e incluso un "bloque de convencionalidad", cambiando para siempre la forma en que se interpretan los derechos en México. Este proceso, aunque gradual, ya comenzó en el análisis efectuado por la Suprema Corte de Justicia de la Nación en el cumplimiento del caso Rosendo Radilla.

\section{Los debates en la Suprema Corte de Justicia de la Nación en torno al cumplimiento de la Sentencia del caso Radilla y la incorporación del "control difuso de convencionalidad"}

El debate de los ministros de la Suprema Corte de Justicia de la Nación en torno a si el Poder Judicial de la Federación resulta obligado o no al cumplimiento de lo señalado por la sentencia en el caso Radilla se

20 de mayo de 2007, publicada en el Semanario Judicial de la Federación y su Gaceta”: TRATADOS INTERNACIONALES. SON PARTE INTEGRANTE DE LA LEY SUPREMA DE LA UNIÓN Y SE UBICAN JERÁRQUICAMENTE POR ENCIMA DE LAS LEYES GENERALES, FEDERALES Y LOCALES, INTERPRETACIÓN DEL ARTÍCULO 133 CONSTITUCIONAL".

168 Una excelente documentación y sobre todo reflexión de este proceso que llevó a la reforma del Artículo $1^{\circ}$ de la Constitución Mexicana puede consultarse en: Caballero Ochoa, José Luis, "La Cláusula de interpretación conforme y el principio pro persona (Artículo $1^{\circ}$, segundo párrafo de la Constitución)" en Carbonell, Miguel y Salazar Pedro (coords.) La reforma Constitucional de Derechos Humanos: Un nuevo paradigma. México, IIJ-UNAM, 2011, p. 103 y ss. Igualmente, en dicha obra consúltese Carbonell, Miguel. "Las obligaciones del Estado en el Artículo $1^{\circ}$ de la Constitución Mexicana”, p. 63 y ss. 
verificó a partir de una consulta a trámite promovida por el entonces ministro presidente Guillermo Ortiz Mayagoitia. ${ }^{169}$

De la sentencia del caso Radilla al menos se desprenden dos obligaciones claras para los jueces mexicanos. Por una parte, se encuentran los cursos de capacitación en derechos humanos que el Poder Judicial Federal tendría que llevar a cabo. Por otra, uno de los puntos más importantes de la sentencia del caso Radilla, se refiere a la aplicación del artículo 57 del Código de Justicia Militar. Al respecto, la Corte IDH dispuso que el Poder Judicial debería ejercer un "control de convencionalidad” ex officio entre las normas internas y la Convención Americana, evidentemente en el marco de sus respectivas competencias y de las regulaciones procesales correspondientes. En esta tarea, el Poder Judicial, para la Corte IDH, debe tener en cuenta no solamente el tratado, sino también la interpretación que del mismo ha hecho la Corte Interamericana, intérprete última de la Convención Americana. ${ }^{170}$ Este ejercicio de control de la convencionalidad eventualmente llevaría al juez nacional mexicano a no aplicar dicho precepto del Código de Justicia Militar por ser contrario a la interpretación que ha dispuesto la Corte IDH del mismo en materia de fuero militar. Esta obligación, además, es general respecto a toda la jurisprudencia de la Corte Interamericana. ${ }^{171}$

La consulta dio lugar al Expediente 489/2010 respecto al que el ministro José Ramón Cossío Díaz propuso un proyecto de resolución acorde con las exigencias del caso. En la discusión pública del proyecto los días 31 de agosto, 2, 6 y 7 de septiembre de 2010, se abordaron básicamente dos temas: primero, si una sentencia internacional es o no vinculante para la Suprema Corte de Justicia de la Nación, y segundo, si la Sentencia de la Corte IDH en el caso Rosendo Radilla tiene o no

169 Ferrer Mac-Gregor, Eduardo y Silva García, Fernando, op. cit., p. 37.

170 Corte IDH, Caso Radilla Pacheco vs. México, Excepciones Preliminares, Fondo, Reparaciones y Costas, sentencia del 23 de noviembre de 2009, Serie C, núm. 209339.

171 Respecto a los alcances del control de convencionalidad véase por una parte el ya citado voto razonado del juez Eduardo Ferrer Mac-Gregor Poisot en el Caso Cabrera García y Montiel Flores vs. México, Excepción Preliminar, Fondo, Reparaciones y Costas, sentencia del 26 de noviembre de 2010, Serie C, núm. 220, y por otra, Castilla, Karlos, "El control de convencionalidad: un nuevo debate en México a partir de la sentencia del caso Radilla Pacheco”, Anuario Mexicano de Derecho Internacional, vol. XI, 2011, pp. 593-624. 
eficacia directa y si debe ser cumplida o no por los jueces nacionales sin mediación o coordinación con el Poder Ejecutivo y el Legislativo para esos efectos. En los debates no se llegó a una conclusión definitiva y el proyecto fue desechado. ${ }^{172}$

La discusión volvió en julio de 2011 a la Suprema Corte de Justicia de la Nación como la Consulta a Trámite Expediente Varios 912/2010 relacionada con el Caso Rosendo Radilla. Sin embargo, había una diferencia fundamental en los parámetros en los que esta segunda discusión tuvo lugar, ya que con la reforma constitucional al artículo 1 o. constitucional, párrafo segundo, en esta ocasión los ministros tenían la obligación constitucional expresa de analizar lo ordenado en el caso de Rosendo Radilla siguiendo el principio pro persona y teniendo que realizar una interpretación conforme entre lo dispuesto en la Constitución y los tratados internacionales involucrados en el caso y su interpretación por parte de la Corte IDH.

El Pleno de la Suprema Corte de Justicia de la Nación resolvió que se cumpliría con los términos de la sentencia del caso Radilla Pacheco y dispuso que los jueces del Estado mexicano deberán aplicar, en casos futuros, el criterio de restricción del fuero militar, en cumplimiento de la sentencia del caso Rosendo Radilla Pacheco y en aplicación del artículo 1o. constitucional.

Más aun, la Suprema Corte determinó que los juzgadores de todo el país están obligados a verificar que las leyes que aplican se ajustan a la Constitución federal y a los tratados internacionales sobre derechos humanos, es decir, están obligados a realizar un control de convencionalidad dentro de un modelo de control difuso de constitucionalidad. Dicho control difuso (de constitucionalidad y convencionalidad) deberá realizarse entre las normas de derecho interno, en relación con la Constitución federal y la Convención Americana sobre Derechos Humanos, tomando en cuenta no solamente su texto sino también a la interpretación realizada por la Corte Interamericana. En ese sentido, la Suprema Corte de Justicia de la Nación resolvió que los jueces de todo el país podrán dejar de aplicar al caso concreto las normas que resulten contra-

172 Un análisis puntual de dichas discusiones puede ser consultado en Ferrer Mac-Gregor, Eduardo y Silva García, Fernando, op cit., pp. 38 y ss. 
rias a la Constitución federal o los tratados internacionales, sin que ello implique una declaración de inconstitucionalidad, que sigue reservada a la justicia federal. ${ }^{173}$

Las decisiones respecto a este tema en la Suprema Corte implican un paso adelante por demás innovador y verdaderamente un hito en la historia judicial del país. Habrá que esperar que dichos criterios puedan efectivamente ser aplicados por el resto de los jueces tanto a nivel federal como local y no queden como un buen precedente aislado que no tenga un impacto real, como sucedió con lo decidido en torno a la controversia constitucional 33/2002.

\section{Las iniciativas de ley que tendrían por objeto el cumplimiento} de la sentencia del caso Radilla: ¿estamos evitando y corrigiendo los errores del pasado?

A partir de las medidas de reparación del caso Radilla, el Poder Legislativo Federal tiene la obligación de modificar el artículo 57 del Código de Justicia Militar y el tipo penal del delito de desaparición forzada de personas previsto en el artículo 215-A del Código Penal Federal.

En el cumplimiento de estas obligaciones se puede mencionar que si bien han sido presentadas varias iniciativas con el fin acatar el fallo de la Corte IDH en el Caso Radilla, según el Sistema de Información Legislativa de la Secretaría de Gobernación, hasta mediados de 2011, ninguna había sido dictaminada en Comisiones en la Cámara de origen. ${ }^{174}$

173 Véase Suprema Corte de Justicia de la Nación. Resolución dictada por el Tribunal Pleno en el expediente varios 912/2010 y Votos Particulares formulados por los ministros Margarita Beatriz Luna Ramos, Sergio Salvador Aguirre Anguiano y Luis María Aguilar Morales; así como Votos Particulares y Concurrentes de los Ministros Arturo Zaldívar Lelo de Larrea y Jorge Mario Pardo Rebolledo. Diario Oficial de la Federación, 4 de octubre de 2011, p. 51 y ss. Las versiones estenográficas de las discusiones se encuentran disponibles en: www.scjn.gob.mx. Asimismo, véase: Suprema Corte de Justicia de la Nación, "Restringe SCJN Fuero Militar, en cumplimiento con la Sentencia emitida por la Corte Interamericana de Derechos Humanos en el Caso Radilla Pacheco”, Comunicado de Prensa No. 127/2011, 14 de julio de 2011.

174 Cfr. Sistema de Información Legislativa de la Secretaría de Gobernación, disponible en: http: / /sil.gobernacion.gob.mx. 
Respecto a las modificaciones al artículo 57 del Código de Justicia Militar hasta mediados de 2011 se habían presentado seis iniciativas. ${ }^{175}$ Dentro de estas iniciativas destaca la presentada el 19 de octubre de 2010 por el Ejecutivo Federal en la que se proponen "reformas en materia de fuero militar para que los integrantes del Ejército que cometan los delitos de desaparición forzada de personas, violación y tortura sean investigados por denuncias anónimas y juzgados por tribunales civiles". ${ }^{176}$

La misma Corte Interamericana de Derechos Humanos en mayo de 2011 tuvo la oportunidad de analizar dicha iniciativa con oportunidad de la supervisión del cumplimiento de la sentencia del caso Rosendo Radilla. En dicha oportunidad la Corte IDH señaló que "la iniciativa presentada e[ra] insuficiente pues no cumple plenamente con los estándares indicados en la Sentencia”, reiterando que las violaciones de derechos humanos cometidas por militares en contra de civiles no pueden ser objeto de la competencia de la jurisdicción militar. ${ }^{177}$ Igualmente, la Corte IDH criticó esta iniciativa presentada por el Ejecutivo ya que le daba validez a las actuaciones del ministerio público militar antes de su “desglose" al fuero ordinario. Al respecto la Corte IDH señaló que en la sentencia del caso Radilla, se hace alusión no sólo a la incompetencia de la jurisdicción militar para juzgar y, eventualmente, sancionar a los responsables, sino también a la incompetencia del fuero militar para la investigación de todo hecho que sea constitutivo de violaciones de derechos humanos de civiles. ${ }^{178}$

En este sentido, cabe aclarar que el mandato de la Corte IDH fue específico en señalar en el caso Radilla que la jurisdicción penal militar no era el fuero competente para investigar y, en su caso, juzgar y sancionar

175 Idem.

176 Poder Ejecutivo Federal. Iniciativa de Ley "Que reforma, deroga y adiciona diversas disposiciones del Código de Justicia Militar, de la Ley Orgánica del Poder Judicial de la Federación, del Código Penal Federal, del Código Federal de Procedimientos Penales y de la Ley que Establece las Normas Mínimas sobre Readaptación Social de Sentenciados”. Cámara de Origen: Cámara de Senadores, presentada el 19 de octubre de 2010.

177 Corte IDH, Caso Radilla Pacheco vs. México, Supervisión de Cumplimiento de Sentencia, Resolución de la Corte Interamericana de Derechos Humanos, 19 de mayo de 2011, párr. 21.

178 Ibidem, p. 22. 
a los autores de violaciones de derechos humanos ${ }^{179}$ en general, sin especificar qué tipo de violaciones. Por si quedara duda de la incompatibilidad de realizar una lista taxativa de violaciones a derechos humanos, en el caso Cabrera García y Montiel Flores se señaló específicamente que la incompetencia de la justicia militar para conocer de casos de violación a derechos humanos se aplicaba "no sólo para casos de tortura, desaparición forzada y violación sexual, sino a todas las violaciones de derechos humanos”. ${ }^{180}$ Más aún, la Corte IDH ha señalado reiteradamente que la jurisdicción penal militar en los Estados democráticos, en tiempos de paz, ha tendido a reducirse e incluso a desaparecer, por lo que en caso de que un Estado la conserve, su utilización debe ser mínima. ${ }^{181}$

En cuanto a la tipificación del delito de desaparición forzada de personas en la LXI Legislatura se habían presentado, hasta mediados de 2011, alrededor de 10 iniciativas en relación con dicho tema, entre propuestas de reforma a la Constitución federal, a la Ley Orgánica del Poder Judicial de la Federación y al Código Penal Federal. De dichas iniciativas, sólo cinco irían en el sentido de cumplir con lo ordenado por la Corte IDH, el resto discute y propone reformas respecto a otros aspectos de este delito. ${ }^{182}$

En el procedimiento de supervisión de cumplimiento de la sentencia del Caso Radilla ante la Corte IDH, el Estado mexicano manifestó que en la misma iniciativa del Ejecutivo ya antes mencionada "se inclu[ían] las reformas al Código Penal Federal en materia de desaparición forzada...”. ${ }^{183} \mathrm{Al}$ respecto, la Corte IDH limitó su análisis de esta iniciativa a únicamente los dos elementos del tipo penal de desaparición forzada de personas que había encontrado que no eran compatibles con la Convención Interamericana en la materia, ya mencionados líneas arri-

179 Corte IDH, Caso Radilla Pacheco vs. México, Excepciones Preliminares, Fondo, Reparaciones y Costas, sentencia del 23 de noviembre de 2009, Serie C, núm. 209, párr. 273.

180 Corte IDH, Caso Cabrera García y Montiel Flores vs. México, Excepción Preliminar, Fondo, Reparaciones y Costas. Sentencia de 26 de noviembre de 2010, Serie C, núm. 220, párr. 198.

181 Corte IDH, Caso Radilla Pacheco vs. México, Excepciones Preliminares, Fondo, Reparaciones y Costas, sentencia del 23 de noviembre de 2009, serie C, núm. 209, párr. 272.

182 Cfr. Sistema de Información Legislativa de la Secretaría de Gobernación, op. cit.

183 Corte IDH, Caso Radilla Pacheco vs. México, Supervisión de Cumplimiento de Sentencia, Resolución de la Corte Interamericana de Derechos Humanos, 19 de mayo de 2011, párr. 23. 
ba. ${ }^{184}$ En su análisis, la Corte determinó que en su propuesta de reforma, el gobierno mexicano había integrado los elementos indicados por el Tribunal para una adecuada tipificación del delito de desaparición forzada conforme a la Convención Interamericana sobre Desaparición Forzada de Personas. ${ }^{185}$

A pesar de la aprobación que ha dado la Corte IDH a la propuesta del Ejecutivo aún se tienen que poner en la mesa y discutir varios aspectos que no fueron analizados por la Corte IDH. Así, por ejemplo, poco se ha discutido respecto a una eventual revisión que se tendría que realizar a los tipos penales de desaparición forzada de personas a nivel estatal, algo que se tendría que hacer de manera oficiosa con el fin de cumplir con las obligaciones internacionales generales de México en el sistema interamericano de derechos humanos.

Desafortunadamente, en los tiempos que han seguido a la notificación de la sentencia del Caso Radilla, pareciese que el debate legislativo lejos de centrarse en cómo reducir el fuero militar acotándolo conforme a los estándares internacionales se ha centrado en cómo ampliarlo por medio de la modificación a la Ley de Seguridad Nacional que eventualmente permitiría que las fuerzas armadas tuvieran mayores atribuciones en materia de seguridad pública y lucha contra el narcotráfico. ${ }^{186}$ Según datos del Sistema de Información Legislativa, a mediados de 2011 se habían presentado 11 iniciativas respecto a este tema, en todos los sentidos. ${ }^{187}$ Un elemento que debería orientar estas discusiones es la observación de la Corte IDH cuando indicó en el caso de los campesinos ecologistas que "en algunos contextos y circunstancias, la alta presencia militar acompañada de intervención de las Fuerzas Armadas

184 Ibidem, párr. 26.

185 Ibidem, párr. 27.

186 La iniciativa de Ley que modificaría la Ley de Seguridad Nacional ha sido duramente criticada por sectores importantes de la sociedad civil, entre otras razones, por no cumplir con lo ordenado por la Corte IDH en el caso Rosendo Radilla. Cfr. Consulta y Dictamen de la Ley de Seguridad Nacional, Comunicado de Prensa de 30 de Julio de 2011 firmado por organizaciones de la sociedad civil.

${ }_{187}$ Cfr. Sistema de Información Legislativa de la Secretaría de Gobernación, op. cit. 
en actividades de seguridad pública, puede implicar la introducción de un riesgo para los derechos humanos". ${ }^{188}$

\section{REFLEXIONES FINALES}

El valor de las palabras es inconmensurable. Rosendo Radilla fue desaparecido por agentes del Estado mexicano para acallar por siempre su voz de protesta en contra de las arbitrariedades que fueron cometidas durante la "guerra sucia”. Los criminales fracasaron. El legado de vida y obra de Rosendo Radilla hace recordar aquél poema de Ramón López Velarde en donde se describen los panoramas desoladores dejados por las batallas libradas durante la Revolución mexicana, y cómo a partir de dichos actos se hizo para los pobladores de esos lugares imposible regresar. Desafortunadamente, esos mismos escenarios los seguimos viviendo casi 100 años después.

En este momento histórico es importante recordar la deuda que como sociedad tenemos con las víctimas de graves violaciones de derechos humanos y sus familiares, y la importancia de procurar como sociedad una reconciliación basada en la verdad, la justicia y la reparación.

El derecho internacional, y en particular, el sistema interamericano de derechos humanos, han demostrado ser una herramienta útil — no la única - para lograr estos fines en escenarios de justicia transicional. ${ }^{189}$ Así, con el propósito de compatibilizar nuestro marco jurídico en materia de desaparición forzada de personas es indispensable cumplir con la sentencia del Caso Radilla, tanto en sus medidas de reparación como en todos sus puntos de derecho. Dentro de este marco, lo mismo deberá ocurrir con lo dispuesto por la Corte IDH en los otros casos decididos

188 Corte IDH, Caso Cabrera García y Montiel Flores vs. México, Excepción Preliminar, Fondo, Reparaciones y Costas, sentencia del 26 de noviembre de 2010, Serie C, núm. 220. párr. 86.

189 Respecto al impacto del Sistema Interamericano de Derechos Humanos en materia de justicia transicional véase Josi, Claudia (coord.), Justicia transicional en América Latina. Primer Informe del grupo de trabajo "Justicia Transicional", Sociedad Latinoamericana para el Derecho Internacional, 2010, 60 pp. Disponible en: http://www.lasil-sladi.org/sladi-lasil-justicia-tran sicional.pdf. 
respecto a México. Esto sobre todo, para atender a las víctimas y sus familiares que han padecido de estas graves violaciones a sus derechos humanos. ${ }^{190}$

Igualmente, será necesario que no sólo los ministros de la Suprema Corte de Justicia de la Nación, sino todos los jueces del país tomen en serio el nuevo paradigma constitucional respecto a los derechos humanos ejerciendo de forma garantista el control difuso de convencionalidad ya mencionado por la Corte IDH.

De igual forma, será necesario revisar la legislación federal y local en materia de desaparición forzada de personas. En este sentido, las precauciones y previsiones que se tomaron en la tipificación del delito de desaparición forzada y en la aprobación de la Convención Interamericana sobre Desaparición Forzada de Personas, no tienen sentido en la actualidad, ya que si bien, en su momento sirvieron para lograr los consensos necesarios para su aprobación, ahora se cuenta con un mandato constitucional y convencional que nos obliga ir más allá de esos supuestos. De ahí que exista la necesidad de que los puntos de derecho del caso Radilla "irradien" el ordenamiento jurídico nacional. ${ }^{191}$

Por último, habría que rescatar las palabras de Tita Radilla Ramírez, hija de Rosendo Radilla quien a un año de emitida la sentencia en el caso de su padre afirmó que: "Llegará el día, lo sabemos, en que podamos decir ¡la desaparición forzada ya no existe!, y será porque se han esclarecido todos los casos, porque ésta práctica no se debe dar jamás”. Esperamos que pronto así sea.

190 A pesar de ser sentencias relativamente recientes, cabe destacar que la mayor parte de las reparaciones ordenadas por la Corte IDH en los casos mexicanos no han sido cumplidas. Cfr. Corte IDH, Caso Radilla Pacheco vs. México, Supervisión de Cumplimiento de Sentencia, resolución de la Corte Interamericana de Derechos Humanos del 19 de mayo de 2011; Corte IDH. Caso Fernández Ortega y otros vs. México, Supervisión de Cumplimiento de Sentencia, Resolución de la Corte Interamericana de Derechos Humanos del 25 de noviembre de 2010, y Corte IDH, Caso Rosendo Cantú y otra vs. México. Supervisión de Cumplimiento de Sentencia, resolución de la Corte Interamericana de Derechos Humanos del 25 de noviembre de 2010.

191 Sobre problemas y perspectivas de la tipificación del delito de desaparición forzada de personas consúltese: Ambos, Kai (coord.), Desaparición forzada de personas. Análisis comparado e internacional, Bogotá, GTZ, 2009. 
Ambos, Kai (coord.), Desaparición forzada de personas. Análisis comparado e internacional, GTZ, Bogotá, 2009.

Berman, Maureen y Clark, Roger, "State terrorism: Disappearances", Rutgers Law Journal, núm. 13, 1982.

Bicudo, Helio, The Inter-American Commission on Human Rights and the Process of Democratization in Peru, Human Rights. Brief, núm. 9.

Brody, Reed y GONZÁLEZ, Felipe. Nunca más: An analysis of International Instruments on “Disappearances”, Human Rights. Quaterly, núm. 9, 1997.

CABAllero OCHOA, José Luis, La Cláusula de interpretación conforme y el principio pro persona (artículo 1o., segundo párrafo de la Constitución), (en prensa).

Cançado Trindade, Antonio Augusto, The Case-Law of the Inter-American Court of Human Rights: An Overview, en Studi di Diritto Internazionale in Onore di Gaetano Arangio-Ruiz, Napoli, vol. III, 2004.

Carbonell, Miguel, "Las obligaciones del Estado en el artículo 1o. de la Constitución mexicana”, en CARBOnell, Miguel y SAlazar, Pedro (coords.), La reforma constitucional de derechos humanos: un nuevo paradigma, México, UNAM, 2011.

CARrillo, Arturo J., "Bringing International Law Home: The Innovative role of Human Rights Clinics in the Transnational Legal Process", Columbia Human Rights Law Review, núm. 35, 2003-2004.

CAstilla, Karlos, "El control de convencionalidad: un nuevo debate en México a partir de la sentencia del Caso Radilla Pacheco”, Anuario Mexicano de Derecho Internacional, vol. XI, 2011.

Ferrer MaC-Gregor, Eduardo y Silva García, Fernando, Jurisdicción militar y derechos humanos. El caso Radilla ante la Corte Interamericana de Derechos Humanos, México, Porrúa-UNAM, 2011.

Fiscalía Especial para Movimientos Sociales y Políticos del Pasado, "Informe Histórico a la Sociedad Mexicana”, 2006.

García RamíreZ, Sergio, "Prólogo" en La sentencia de la Corte IDH. Caso Radilla PachecoVs. Estados Unidos Mexicanos, México, CMDPDH, 2010. , Sergio, La Corte Penal Internacional, México, INACIPE, 2004. 
Josi, Claudia (coord.) Justicia transicional en América Latina. Primer Informe del grupo de trabajo "Justicia Transicional", Sociedad Latinoamericana para el Derecho Internacional, 2010.

LiVermore, J. Daniel y Ramcharan, B. G., Enforced or involuntary Disappearances" An Evaluation of a Decade of United Nations Action, Canadian Human Rights. Year Book, 1989-1990.

MÉNDEZ, Juan E. y VivanCO, José Miguel, “Disappearances and the Inter-American Court: Reflections on a litigation experience", Hamline Law Review, núm. 13, 1990.

PARAYRE, Sonia, "La desaparición forzada de personas como violación continuada de los derechos humanos y su incidencia en la determinación de la competencia Ratione Temporis de la Corte Interamericana de Derechos Humanos", Revista IIDH, vol. 29.

PÉREZ SOlla, María Fernanda, "Enforced Disappearances before Argentinean Tribunals: New Developments in an Endless fight for Justice”, South African Journal on Human Rights, núm. 19, 2003.

Rodley, Nigel S., United Nations Actions and Procedures Against "Disappearances", Summary or Arbitrary Executions, and Torture, Human. Rights. Quaterly, núm. 8, 1986.

Shelton, Dinah, Remedies in International Human Rights Law, 2a. ed. Nueva York, Oxford University Press, 2006.

Singh SETHI, Gobind, “The European Court of Human Rights' Jurisprudence on Issues of Forced Disappearances", Human Rights Brief, núm. 8, 2001.

TAQI, Irum, "Note: Adjudicating Disappearance cases in Turkey: An Argument for Adopting the Inter-American Court of Human Rights' Approach”, 24 Fordham International Law Journal, núm. 24, 2001.

Varios autores, Proyecto de Ley de Amparo Reglamentaria de los artículos 103 y 107 de la Constitución Política de los Estados Unidos Mexicanos, México, Suprema Corte de Justicia de la Nación, 2000. 